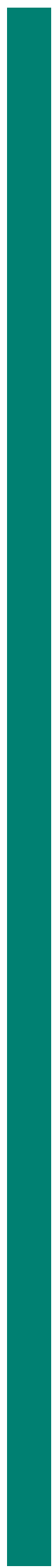

\title{
Safeguarding the Nation's Digital Memory
} Project Evaluation Report for the National Archives

FINAL

\author{
February 2021 \\ Jen Mitcham, Amy Currie, William Kilbride \\ http://doi.org/10.7207/op21-01
}

The Safeguarding the Nation's Digital Memory project was funded by the National Lottery Heritage Fund. 


\section{Table of Contents}

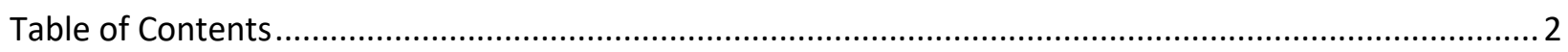

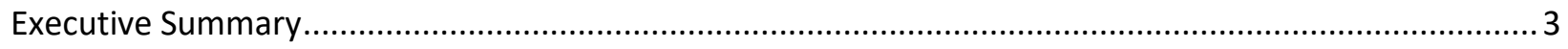

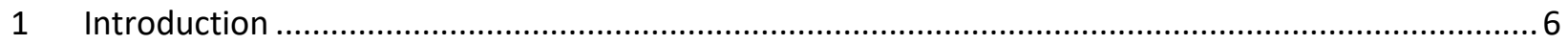

1.1 Safeguarding the Nation's Digital Memory......................................................................

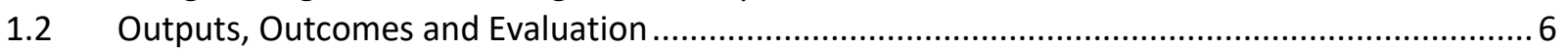

1.3 Research Questions ……………………………………………………………...

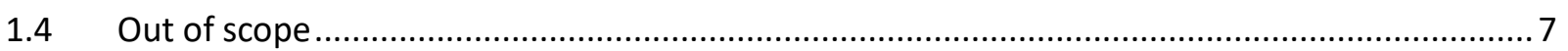

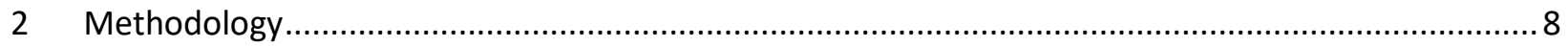

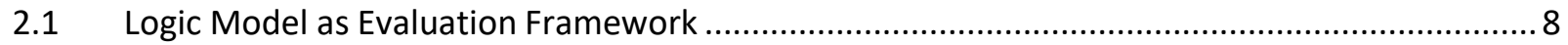

2.1.1 Outcome 1: A wider range of people will be involved in heritage. ...................................10

2.1.2 Outcome 2: Heritage will be in better condition.........................................................11

2.1.3 Outcome 3: People will have developed skills...........................................................12

2.1.4 Outcome 4: The funded organization will be more resilient. ...........................................13

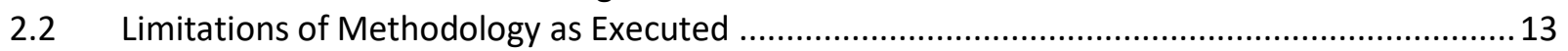

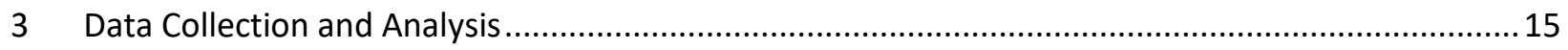

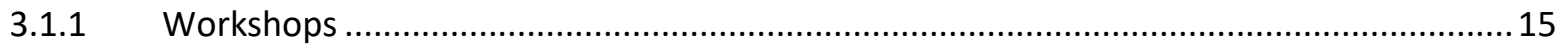

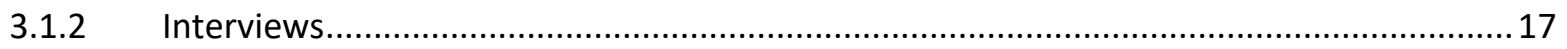

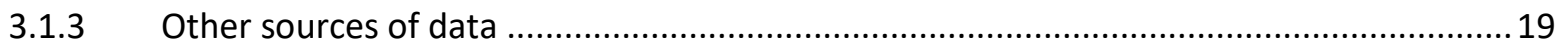

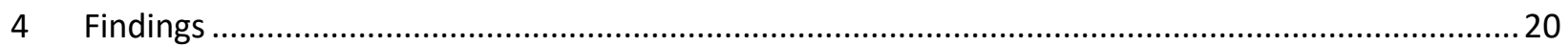

4.1 Outcome 1: A wider range of people will be involved in heritage. ………………………......2

4.2 Outcome 2: Heritage will be in better condition. ………………………………………...22

4.3 Outcome 3: People will have developed skills......................................................................26

4.4 Outcome 4: The funded organization will be more resilient. ..................................................30

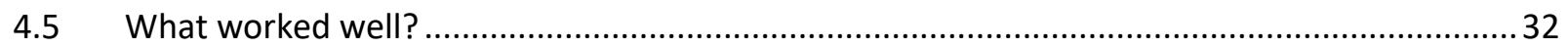

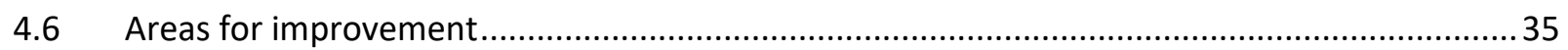

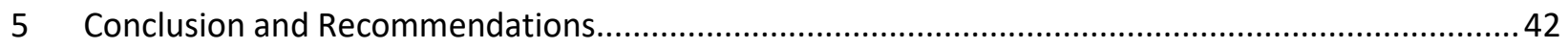

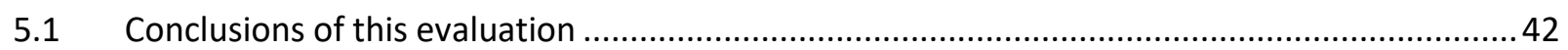

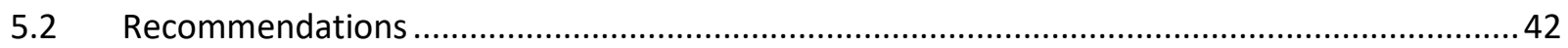

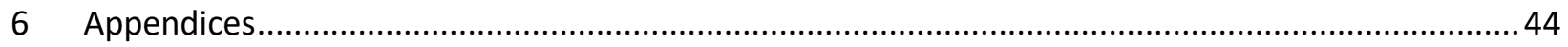

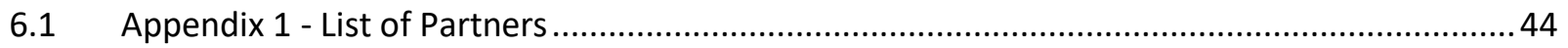

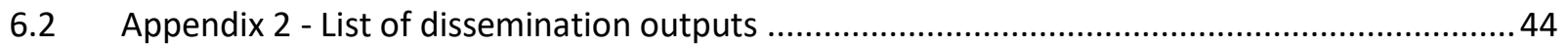

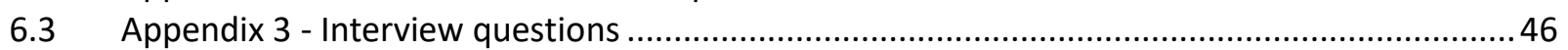

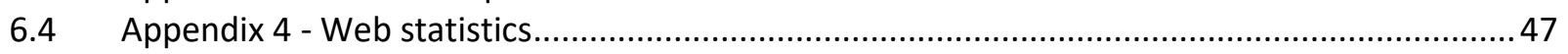

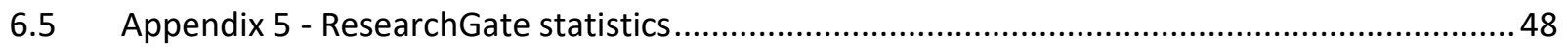

6.6 Appendix 6 - Twitter statistics ................................................................................ 49

6.7 Appendix 7 - Digital Preservation Awards 2020 feedback .....................................................50 


\section{Executive Summary}

This report presents the results from an evaluation of the Safeguarding the Nation's Digital Heritage project. This project, funded by the National Lottery Heritage Fund (NLHF) and jointly executed by The National Archives and the University of Warwick with partners ${ }^{1}$, delivered the 'DiAGRAM' (the Digital Archives Graphical Risk Assessment Model) decision support tool which models and quantifies risks to digital content. The project began in January 2020 and was completed in December 2020, with a postproject evaluation being completed in February 2021. The project dates coincide with the global COVID19 pandemic. Consequently, the project team faced challenges that could not have been anticipated from the outset, and the project timeline was extended to take account of this.

This report presents the findings of an independent evaluation of the project undertaken by the Digital Preservation Coalition (DPC). It sets the context for evaluation in the framework of NLHF recommendations for a logic model that distinguishes outputs from outcomes. It provides a set of research questions derived from the project's declared outcomes:

- In what ways has the 'Safeguarding the Nation's Digital Heritage' project and the DiAGRAM tool involved a wider range of people in heritage?

- Are digital archives in better condition because of the project and is that improvement likely to be sustained?

- Who was involved in the project and what new skills have they learned?

- Is The National Archives more resilient because of the DiAGRAM tool and in what ways? It then provides an overview of the methods employed for the evaluation, key findings as they relate to the four primary project outcomes established at the outset, strengths and weaknesses of the project, and conclusions. Several appendices are included to further evidence points raised within the evaluation.

The evaluation reaches the conclusion that, despite the disruptions of the pandemic, the project has met and in several respects exceeded its declared outcomes. This conclusion is qualified insofar as the short timescale of the evaluation is incommensurate with the longer timescale of changing professional practice.

The evaluation therefore makes nine recommendations:

\section{Elaborate and refine the model.}

The model underlying the data is partial and could be further elaborated in breadth and depth. such as the addition of more nodes of more and increasingly granular evidence. This could be most readily achieved with participation from other national and UK archives to widen its applicability within the domain supported by NLHF.

\section{Revise and update the model with global insights.}

The evaluation has shown the value of international participation, an unanticipated benefit of the pandemic. Digital preservation is a global challenge not limited to the UK; therefore, the tool can

\footnotetext{
${ }^{1}$ See Appendix 1 for the list of partners
} 
achieve more impact abroad and become more accurate and precise if efforts are made to involve archives and sectoral partners around the world.

\section{Maintain active communications.}

Both tool and the model are still at an early stage in terms of their deployment. For this reason, a longer-term communications strategy should be developed to support continued adoption. This should include published case studies that describe deployment in a range of different contexts and further extend familiarity with the underlying statistical method.

\section{Support users with training.}

In addition to case studies and wider communications, it is recommended that the project team investigate the provision of training materials or periodic training events that orient and support new users. This invites partnership with training providers to include the tool within relevant training materials and curricula.

\section{Design programmatic review and feedback on the model.}

The model and the data underpinning the tool fluctuate over time and therefore need periodic refreshment and updating lest they become less useful and ultimately obsolete. A programme of refreshment should be developed and include definition of roles, responsibilities and deliverables. Options to develop online methods of gathering community data and feedback should also be included in this. Such an action would further assist communication.

6. Maintain the DiAGRAM tool in line with accessibility and technical requirements. Although strictly outwith the terms of this evaluation, the DiAGRAM tool which delivers the model is also subject to obsolescence. This should be monitored with particular attention paid to accessibility. For example, the app should meet Government Digital Service (GDS) accessibility standards to be launched beyond a beta version. Moreover, it is to be anticipated that mandated requirements for accessibility and technology will continue to emerge. Efforts should therefore be made to ensure the apps ongoing compliance with these standards.

\section{Scope the opportunities for system development and integration.}

There is scope to develop the tool with more advanced functionality to encourage learning (and more nuanced scoring) as well as to allow archivists with specialist statistical skills to make more use of the tool. Integration with the broad and emergent suite preservation planning tools would also bring advantages. A research and development programme should explore these opportunities with partners.

\section{Sustain and build the community.}

The Safeguarding the Nations Digital Memory Project has worked with an important but necessarily small cross section of the archive community. Sustaining then building this group into a user community will create a virtuous circle: it will enhance the breadth of input thus improving the tool; and it will help the community to achieve its strategic goals of improved digital preservation. The DPC is a readily available catalyst for such community building.

\section{Support capability in the sector.}

It is relatively unusual for NLHF to support a project with explicit aims to support capability in the sector or to help with the development of new tools rather than the funding of new digital content. This is badly needed if the NLHF is to achieve its wider goals with respect to preserving digital content in the long term. NLHF should therefore investigate programmatic support to digital capability in the sector. 


\section{Acknowledgements}

The DPC gratefully acknowledges the support offered received in the completion of this evaluation. Special thanks are due to the project team Martine Barons, Thais Fonseca, Alex Green, Hannah Merwood and David Underdown, and the project partners represented by Sue Breakell, Jodie Double, Heather Forbes, Sam Johnston and Tamara Thornhill. We are grateful to the interviewees for their willingness to participate and for granting permission to publish excerpts from the interviews including Heather Tompkins, Angela Beking, Helen Dafter and John Sheridan, and also to the many participants in the workshops and dissemination events who provided feedback. We are grateful to members of the DPC team who have commented on and improved this report, and to the National Lottery Heritage Fund who funded the evaluation. 


\section{Introduction}

\subsection{Safeguarding the Nation's Digital Memory}

The Nation's digital heritage is rich, complex and fragile and is under threat from rapidly evolving technology, outdated policies and a skills gap across the archives sector. To preserve this heritage for future generations, the sector must understand and navigate a vast and ever-shifting risk landscape. The Safeguarding the Nation's Digital Memory project, funded by the National Lottery Heritage Fund (NLHF) and based at The National Archives (TNA) in Kew, highlighted the shared risk management challenges associated with digital preservation, recognizing that no single archive was equipped to address these challenges in isolation.

The project employed a collaborative approach to documenting, articulating, and managing digital preservation risk. It brought established statistical risk management methods into the digital heritage sphere with the aim of creating a structured evidence base, drawn from a shared pool of collective experience. This was used to map and explain the interconnected network of risks faced by digital materials, professional responses to those risks and the efficacy of these responses for the preservation of digital materials. By doing this, the project articulated a holistic understanding of digital preservation risks and responses, enabling archivists to prioritize threats and choose the most effective actions to combat them. The collective approach also allowed flexibility to accommodate the diverse contexts and priorities of different organizations, communities and collections. The resulting methods and tools have been made available to the entire archives sector and digital preservation community, helping archivists and heritage managers in all sectors make better decisions for the future of our digital heritage. The primary output of this project has been the creation of DiAGRAM (the Digital Archives Graphical Risk Assessment Model) - a tool now freely available for the digital heritage community to use to assess risk to digital collections and inform mitigation decisions.

\subsection{Outputs, Outcomes and Evaluation}

The DiAGRAM tool and the materials used to create it are the main outputs from the project and have been delivered on time (with respect to the revised project timeline) and to a standard which meets or exceeds the specification for a viable product. These outputs are necessary but not sufficient conditions to facilitate the preservation of digital materials. The tools need to be adopted and deployed before the wider ambition can be achieved. Consequently, the project established four primary outcomes at the proposal stage, matching the project to the NLHF's strategic objectives:

1. A wider range of people will be involved in heritage;

2. Heritage will be in better condition;

3. People will have developed skills;

4. The funded organization will be more resilient. 
These four outcomes match the project to the NLHF's purpose to fund projects that make a difference for heritage, people and their communities.

The collaborative approach for the project also extended to planning the project evaluation. Whilst the NLHF explains that project evaluations involve project level self-evaluations to assess whether a project has spent its money appropriately and has achieved the desired outcomes, this project recruited the Digital Preservation Coalition (DPC) to evaluate the extent to which the project met or exceeded its stated outcomes.

The DPC is a global not-for-profit organization which helps its members achieve a secure digital legacy enabling members to deliver resilient long-term access to digital content and services, helping them to derive enduring value from digital collections and raising awareness of the strategic, cultural and technological challenges they face. DPC Members include The National Archives and the University of Warwick alongside over 100 other organizations involved in the preservation of digital heritage across the world. Member-owned and member-run, it delivers a program designed around member needs and of benefit to the global digital preservation community.

\subsection{Research Questions}

Project Evaluation sought to answer the following questions:

- In what ways has the 'Safeguarding the Nation's Digital Heritage' project and the DiAGRAM tool involved a wider range of people in heritage?

- Are digital archives in better condition because of the project and is that improvement likely to be sustained?

- Have sufficient people been involved to ensure that the tool is credible and of relevance beyond the funded organization?

- Is The National Archives more resilient because of the project and in what ways?

\subsection{Out of scope}

The following matters are out of scope for this evaluation:

- Value for money or financial matters relating to the project;

- Counterfactual assessment of what NLHF or the partners might have done had they not engaged in this project;

- Software quality and acceptance testing of the DiAGRAM tool. 


\section{Methodology}

\subsection{Logic Model as Evaluation Framework}

This evaluation is based on the NLHF evaluation guidance ${ }^{2}$ which recommends the following principles:

1. There should be clear and logical links between activities, outputs and outcomes across the project;

2. Evaluation should be methodical and appropriate to the audience;

3. Data should be analyzed robustly to provide evidence of outcome;

4. Evaluation should be free from bias and objective;

5. Evaluation Results should be presented clearly and sufficiently;

6. Provide clear conclusions and recommendations to help enable stakeholders to identify and apply any lessons learned.

A logic model approach has been adopted (as recommended by the NLHF) to incorporate these principles in evaluation. The first and perhaps most important use of the model was as a framework to collect baseline information about the project's planned activities, expected outputs, and anticipated outcomes at the outset which could then be compared with data collected and analyzed during and after completion. In other words, the use of the model for the identification and articulation of the underlying logic behind anticipated outcomes at the start of the project provides us with the baseline for the project evaluation that could then be revisited and tested to determine whether those outcomes have occurred or changed. An example of this logic model is illustrated in figure 1.

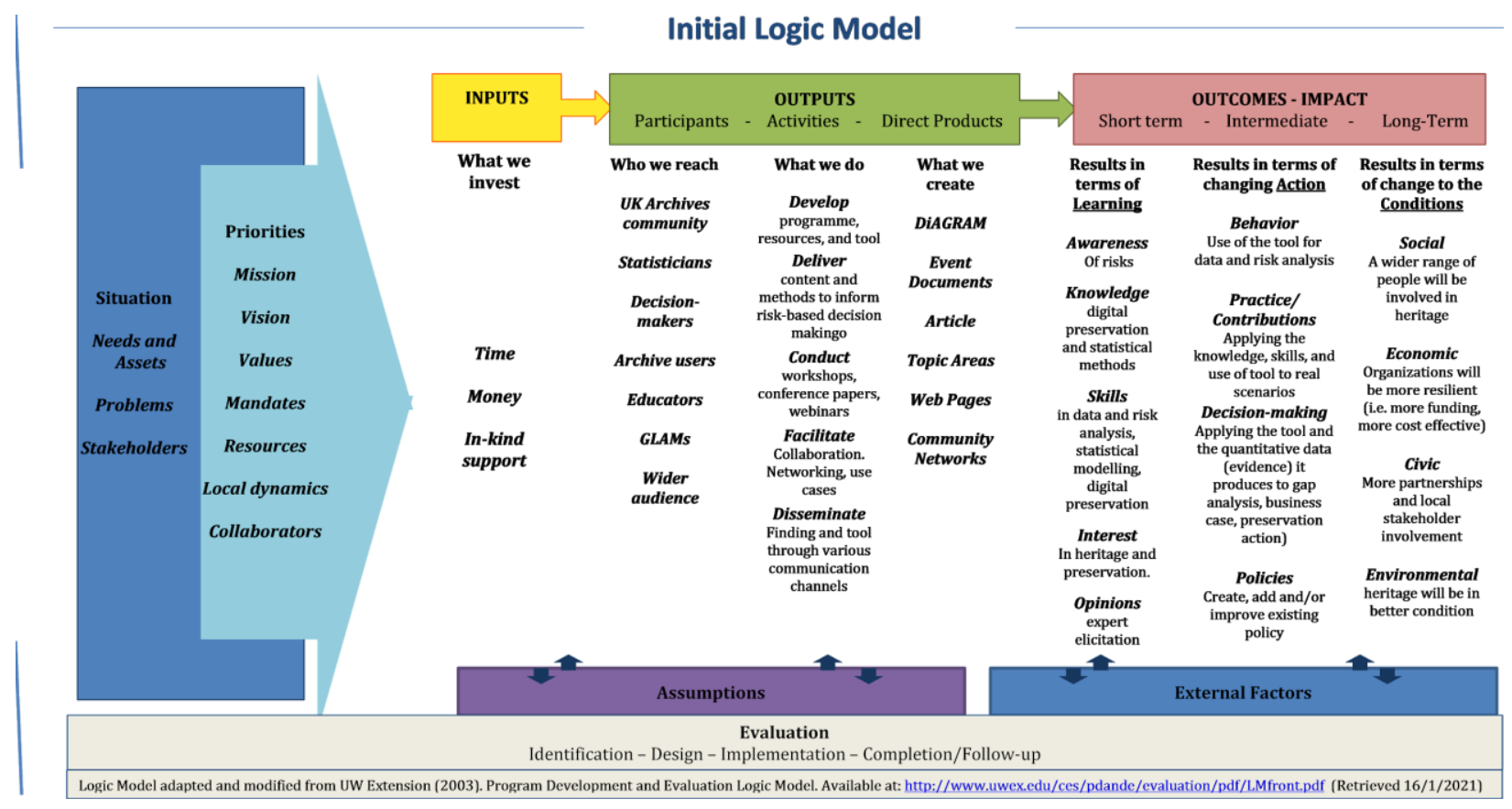

Figure 1: Initial logic model created, to encapsulate and describe project outcomes and impacts

\footnotetext{
${ }^{2}$ https://www.heritagefund.org.uk/good-practice-guidance/evaluation-guidance
} 
The logic model also helped inform the methods and approaches for analyzing and interpreting data collected throughout the project. Both quantitative and qualitative data was collected from multiple sources, including published literature, programme documents, event recordings, attendance numbers, online evaluation forms, social media statistics, and interviews with the project team, partners, and participants. Along with activities, outputs, and outcomes, assumptions and external factors are to be considered within the model, which can bring to light potential biases.

The logic model was elaborated into a separate evaluation framework for each of the four identified primary project outcomes, which were the basis for the research questions which the evaluation answers. The process of developing these models at a more granular level helped the evaluators identify the various elements of the four expected project outcomes established at the outset, creating a foundation for evaluation. The tables below present the logic model as it was applied to each of the four project outcomes prior to analysis. They tabulate project inputs, outputs and expected outcomes along with assumptions and external factors contributing to intended and unintended outcomes.

These logic models provide the basis for the evaluation methodology for the project. They make explicit the sorts of data needed to evidence each outcome and, in turn, they frame the data gathering process. In a larger project, a more intensive evaluation might seek to design different data gathering exercises against different outcomes. In this project, however, the evaluators made the assumption that data can be gathered for all four research questions from the same data gathering process.

Data was therefore gathered from five sources:

- Evaluation of workshops including participant feedback forms during the project

- Semi-structured interviews with participants and stakeholders after the project

- Publications and presentations

- Web and social media data

- Other evidence of external peer review

Of these, the participant feedback and stakeholder interviews are more tightly defined to test progress towards project outcomes, and so are a considerably more useful source. Other sources are welcome but not designed specifically for the assessment of outcomes. The resulting data set is described in chapter three. 


\subsubsection{Outcome 1: A wider range of people will be involved in heritage.}

Research Question: In what ways has the 'Safeguarding the Nation's Digital Heritage' project and the DiAGRAM tool involved a wider range of people in heritage?

\begin{tabular}{|c|c|c|c|c|c|}
\hline \multirow[t]{2}{*}{ 1. Inputs } & \multicolumn{2}{|c|}{ 2. Outputs } & \multicolumn{3}{|c|}{ 3. Outcomes - IMPACT } \\
\hline & Activities & Participation & Short & Medium & Long \\
\hline $\begin{array}{l}\text { Project team's } \\
\text { time } \\
\text { Project } \\
\text { partner's time } \\
\text { DPC's time } \\
\text { Funds for } \\
\text { events and } \\
\text { travel } \\
\text { Professional } \\
\text { networks }\end{array}$ & \multicolumn{2}{|c|}{$\begin{array}{l}\text { Formation of a cross-disciplinary } \\
\text { project team } \\
\text { Programme of dissemination } \\
\text { workshops, conference papers } \\
\text { and webinars to bring the } \\
\text { project work to a wider } \\
\text { audience. } \\
\text { Use of social media and blogs for } \\
\text { dissemination. } \\
\text { DiAGRAM tool available for the } \\
\text { digital archives community to } \\
\text { use to inform their own risk- } \\
\text { based decision making. }\end{array}$} & \multicolumn{3}{|c|}{$\begin{array}{l}\text { In the short term, the inclusion of statisticians } \\
\text { with no prior experience in the heritage } \\
\text { sector in the project team leads directly to } \\
\text { more people being involved in heritage. } \\
\text { In the medium term, the tool created } \\
\text { through this project will be adopted by } \\
\text { archivists and used to quantify risk and } \\
\text { support more effective decision making for } \\
\text { digital archives. Outputs from the tool will } \\
\text { allow managers to understand and be more } \\
\text { accountable for resourcing decisions in } \\
\text { heritage. } \\
\text { In the long term, use of this tool to aid } \\
\text { effective risk-based decision making will } \\
\text { result in better and more accountable } \\
\text { decisions for the preservation of digital } \\
\text { archives which leads to easier access to these } \\
\text { archives thus more people having access to } \\
\text { digital heritage and managers being more } \\
\text { transparent to stakeholders about their } \\
\text { decisions. }\end{array}$} \\
\hline \multicolumn{3}{|c|}{$\begin{array}{l}\text { 4. Assumptions } \\
\text { Given the long time scales at play when working } \\
\text { with archives, the impact of preservation } \\
\text { decisions made now may not demonstrate clear } \\
\text { benefits for many decades to come. However, } \\
\text { digital preservation is path dependent, so } \\
\text { decisions which are made now will have an } \\
\text { impact for better or worse. Future audiences may } \\
\text { be drawn in and become involved in heritage as a } \\
\text { result of our actions to preserve digital archives } \\
\text { today but this cannot be easily measured or } \\
\text { quantified. Evaluation of this outcome must } \\
\text { therefore focus primarily on those outcomes that } \\
\text { can be measured now, and whether these actions } \\
\text { increase or lower the barriers to possible use. }\end{array}$} & \multicolumn{3}{|c|}{$\begin{array}{l}\text { 5. External factors } \\
\text { It can take time for a new tool to be widely } \\
\text { adopted by the archives sector. As a fairly } \\
\text { conservative and often under-resourced } \\
\text { profession, the time that many practitioners } \\
\text { have to experiment with new concepts and } \\
\text { tools that have not yet become mainstream } \\
\text { is limited. It is anticipated that adoption of } \\
\text { the tool will be a gradual process and there } \\
\text { will be few real-world examples of } \\
\text { practitioners using the tool at the time of the } \\
\text { project evaluation. }\end{array}$} \\
\hline
\end{tabular}




\subsubsection{Outcome 2: Heritage will be in better condition.}

Research Question: Are digital archives in better condition because of the project and is that improvement likely to be sustained?

\begin{tabular}{|c|c|c|c|c|c|}
\hline \multirow[t]{2}{*}{ 1. Inputs } & \multicolumn{2}{|c|}{ 2. Outputs } & \multicolumn{3}{|c|}{ 3. Outcomes - IMPACT } \\
\hline & Activities & Participation & Short & Medium & Long \\
\hline $\begin{array}{l}\text { Resources } \\
\text { going in: } \\
\text { Project team's } \\
\text { time } \\
\text { Project } \\
\text { partner's time } \\
\text { DPC's time } \\
\text { Funds for } \\
\text { events and } \\
\text { travel } \\
\text { Professional } \\
\text { networks }\end{array}$ & \multicolumn{2}{|c|}{$\begin{array}{l}\text { Programme of dissemination } \\
\text { workshops, conference papers } \\
\text { and webinars to bring the } \\
\text { project work to a wider } \\
\text { audience. } \\
\text { DiAGRAM tool available for the } \\
\text { digital archives community to } \\
\text { use to inform their own risk- } \\
\text { based decision making. }\end{array}$} & \multicolumn{3}{|c|}{$\begin{array}{l}\text { In the short term. we may see one or two } \\
\text { case studies emerging of organizations using } \\
\text { the tool to help with their decision making } \\
\text { around digital preservation. These case } \\
\text { studies may be located within the funded } \\
\text { organization and wider project team. } \\
\text { In the medium term. the tool created } \\
\text { through this project will be adopted by } \\
\text { archivists and used to quantify risk and } \\
\text { support more effective decision making for } \\
\text { digital archives. Case studies will emerge } \\
\text { beyond the funded organization and project } \\
\text { partners. } \\
\text { In the long term, use of this tool to aid } \\
\text { effective risk-based decision making will } \\
\text { result in better preservation of digital } \\
\text { archives which leads to heritage being in } \\
\text { better condition. }\end{array}$} \\
\hline \multicolumn{3}{|c|}{$\begin{array}{l}\text { 4. Assumptions } \\
\text { It is assumed that decisions made using the tool } \\
\text { created as part of this project will lead to heritage } \\
\text { being in better condition as the tool will provide a } \\
\text { way of more effectively quantifying and } \\
\text { comparing risks than has previously been } \\
\text { available to the digital preservation community. }\end{array}$} & \multicolumn{3}{|c|}{$\begin{array}{l}\text { 5. External factors } \\
\text { Depending on the nature of decisions made } \\
\text { as a result of using the project outputs, it may } \\
\text { be hard to collect real evidence of heritage } \\
\text { being in better condition as the impact of } \\
\text { decisions made now may not be felt for many } \\
\text { years down the line. }\end{array}$} \\
\hline
\end{tabular}




\subsubsection{Outcome 3: People will have developed skills.}

Research Question: Have sufficient people been involved to ensure that the tool is credible and of relevance beyond the funded organization?

\begin{tabular}{|c|c|c|c|c|c|}
\hline \multirow[t]{2}{*}{ 1. Inputs } & \multicolumn{2}{|c|}{ 2. Outputs } & \multicolumn{3}{|c|}{ 3. Outcomes - IMPACT } \\
\hline & Activities & Participation & Short & Medium & Long \\
\hline $\begin{array}{l}\text { Resources } \\
\text { going in } \\
\text { Project team's } \\
\text { time } \\
\text { Project } \\
\text { partner's time } \\
\text { DPC's time } \\
\text { Funds for } \\
\text { events and } \\
\text { travel } \\
\text { Professional } \\
\text { networks }\end{array}$ & \multicolumn{2}{|c|}{$\begin{array}{l}\text { Collaborative and cross- } \\
\text { disciplinary project work will } \\
\text { enable transfer of knowledge } \\
\text { and skills between sectors. } \\
\text { Programme of dissemination } \\
\text { workshops, conference papers } \\
\text { and webinars to bring the } \\
\text { project work to a wider } \\
\text { audience. } \\
\text { DiAGRAM tool available for the } \\
\text { digital archives community to } \\
\text { use to inform their own risk- } \\
\text { based decision making. }\end{array}$} & \multicolumn{3}{|c|}{$\begin{array}{l}\text { In the short term, the project will draw upon } \\
\text { and respond to experts across a range of } \\
\text { archival institutions and develop risk analysis } \\
\text { and statistical modelling skills. Expert } \\
\text { elicitation from specialists and the wider UK } \\
\text { archives community will validate the model } \\
\text { and feedback will improve the tool } \\
\text { The statisticians involved in the project will } \\
\text { also develop knowledge and skills related to } \\
\text { digital preservation and the archives sector } \\
\text { will have a greater awareness of the potential } \\
\text { applications of statistics to heritage. } \\
\text { In the medium term, skills development will } \\
\text { continue across the archives sector as more } \\
\text { organizations apply the tool and techniques } \\
\text { created by the project. } \\
\text { In the long term, as more case studies and } \\
\text { examples of using the tool become available, } \\
\text { and as training on the tool and methods } \\
\text { becomes embedded within digital } \\
\text { preservation training platforms, the use of } \\
\text { the tool will increase, leading to wider } \\
\text { engagement and skills development in the } \\
\text { archives sector in the UK and beyond. }\end{array}$} \\
\hline \multicolumn{3}{|c|}{$\begin{array}{l}\text { 4. Assumptions } \\
\text { It is assumed that those who have attended a } \\
\text { dissemination event or read a publication about } \\
\text { the tool will have developed new skills as a result. } \\
\text { It is assumed that those who have tried the tool, } \\
\text { will also have developed new skills as a result too. } \\
\text { 'Not Made Here' could be a barrier to impact, } \\
\text { especially given the innovation involved and the } \\
\text { uniqueness of TNA. The project has to engage a } \\
\text { large group to be credible. }\end{array}$} & \multicolumn{3}{|c|}{$\begin{array}{l}\text { 5. External factors } \\
\text { Lockdown during the project due to Covid-19 } \\
\text { has changed the types of dissemination and } \\
\text { engagement during the project. Though } \\
\text { online meeting platforms are a good } \\
\text { substitute, it can be challenging to replicate } \\
\text { face-to-face knowledge transfer and harder } \\
\text { to gauge audience reaction and } \\
\text { understanding whilst conveying information. }\end{array}$} \\
\hline
\end{tabular}




\subsubsection{Outcome 4: The funded organization will be more resilient.}

Research Question: Is The National Archives more resilient because of the project and in what ways?

\begin{tabular}{|c|c|c|c|c|c|}
\hline \multirow[t]{2}{*}{ 1. Inputs } & \multicolumn{2}{|c|}{ 2. Outputs } & \multicolumn{3}{|c|}{ 3. Outcomes - IMPACT } \\
\hline & Activities & Participation & Short & Medium & Long \\
\hline $\begin{array}{l}\text { Project team's } \\
\text { time } \\
\text { Professional } \\
\text { networks } \\
\text { Reputation }\end{array}$ & \multicolumn{2}{|c|}{$\begin{array}{l}\text { Data collected through the } \\
\text { expert elicitation process. } \\
\text { DiAGRAM tool available for The } \\
\text { National Archives to use to } \\
\text { quantify their own risk and } \\
\text { inform decision making } \\
\text { DiAGRAM tool available for } \\
\text { project partners and wider } \\
\text { archives community to use to } \\
\text { quantify their own risk and } \\
\text { inform decision making }\end{array}$} & \multicolumn{3}{|c|}{$\begin{array}{l}\text { In the short term, the project will have } \\
\text { increased awareness within the funded } \\
\text { organizations about digital preservation risk, } \\
\text { in particular through creating a data model or } \\
\text { framework for this project and through the } \\
\text { expert elicitation process. } \\
\text { In the medium term, the funded } \\
\text { organizations will have tested the tool on 1-2 } \\
\text { real-world scenario/s to help quantify risks } \\
\text { and inform their decision making. } \\
\text { In the long term, use of the tool will become } \\
\text { 'business as usual' within the funded } \\
\text { organization to help them understand and } \\
\text { mitigate risks to their digital content. A body } \\
\text { of knowledge and use cases from the wider } \\
\text { archive sector will help inform the } \\
\text { development of the tool and the knowledge } \\
\text { base underlying it. }\end{array}$} \\
\hline \multicolumn{3}{|c|}{$\begin{array}{l}\text { 4. Assumptions } \\
\text { In making decisions as a response to the risks to } \\
\text { digital heritage highlighted using the project } \\
\text { outputs, the organization will increase their } \\
\text { resilience. }\end{array}$} & \multicolumn{3}{|c|}{$\begin{array}{l}\text { 5. External factors } \\
\text { It may be hard to collect real evidence of the } \\
\text { organizations being more resilient in the time } \\
\text { frame available due to the gradual rates of } \\
\text { change in this sector. }\end{array}$} \\
\hline
\end{tabular}

\subsection{Limitations of Methodology as Executed}

Evaluation typically establishes performance indicators early in project design, takes measurements throughout the project and provides summative assessment at the end, with an option for formative evaluation at fixed points during the project. Initially, research for this evaluation followed these design principles, with data gathering methodologies scheduled at specific project milestones. This was initiated on schedule in January 2020. However, the effect of the global pandemic which was declared in early 2020 meant that the project team had little choice but to transform their working methodologies. There were three practical impacts on project evaluation: 
- The project was extended by more than six months. Evaluation deadlines had to be reset and work had to be rescheduled.

- Face to face elicitation and dissemination was abandoned. Evaluation had to respond to different kinds of stakeholder engagement, especially through a sustained and expanded programme of videoconferences.

- The project team has not met face to face since January 2020. Project oversight, including this evaluation, has been undertaken in the disrupted and unpredictable contexts of lockdown.

The project team has, however, adapted to these conditions, turning some of the practical constraints into strengths. For example, the move to online dissemination meant participants could join from many different contexts instead of having to travel. In particular, the online workshop programme was altered to enable participation from different time zones around the world. This is important because the digital preservation community is a global community which seeks and develops solutions collaboratively. Consequently, the long term success of the project to some extent depends on deployment and adaptation of the tools beyond UK contexts.

The realities of project execution meant significant changes to the process of data gathering. Nonetheless, the core set of evaluation questions were unchanged.

Irrespective of the pandemic, the evaluation also acknowledges the biases of the authors. The DPC has been involved in this project through the organization of dissemination events as well as conducting this evaluation. Both The National Archives and The University of Warwick are Members of the DPC and as such, the DPC is closely associated with the success of this project and has an ongoing working relationship with members of the project team. Whilst acknowledging this existing relationship, the methodology is fundamentally based on evidence collected and shared without prejudice. The conclusions are therefore objective and balanced, and readers are at liberty to challenge the evaluation in line with the information gathered and presented below. 


\section{Data Collection and Analysis}

The project evaluation took a mixed method approach to data collection and analysis, with a focus on the project outcomes and research questions defined through the logic models above. Some of the challenges relating to this evaluation have been mentioned in the methodology (Chapter 2), such as the outbreak of the COVID-19 pandemic. Irrespective of the pandemic, the defined timeline of the project and the extended timescales within which the outcomes can realistically be measured are mismatched. The data sources collected and discussed here focused on shorter term aspects that could be more easily measured in the timeframe available, such as audiences reached, feedback received and expressed intentions to use the DiAGRAM tool.

The data sources referred to in this report are outlined below with a brief discussion of how they were collected and analyzed.

\subsubsection{Workshops}

A number of online workshops, webinars and meetings were organized throughout the project and it was considered a key part of this evaluation to collect feedback from attendees. It should be noted that all the workshops were initially planned as face-to-face events with a single recorded webinar. In practice, all but one event, including the extended two-day elicitation workshop, were moved online, in some cases at very short notice and with only partial confidence of success. A full list of dissemination and outreach events is included in Appendix 2, but those events for which feedback was collected are listed below.

\begin{tabular}{|l|l|l|l|l|l|}
\hline Name of event & $\begin{array}{l}\text { Format of } \\
\text { event }\end{array}$ & $\begin{array}{l}\text { Date } \\
\mathbf{( 2 0 2 0 )}\end{array}$ & Audience & $\begin{array}{l}\text { No of } \\
\text { people } \\
\text { signed up * }\end{array}$ & $\begin{array}{l}\text { No of } \\
\text { evaluation } \\
\text { forms } \\
\text { received }\end{array}$ \\
\hline $\begin{array}{l}\text { Online elicitation } \\
\text { workshop }\end{array}$ & $\begin{array}{l}\text { Expert } \\
\text { workshop } \\
\text { (2 days) }\end{array}$ & $\begin{array}{l}\text { 28-29th } \\
\text { April }\end{array}$ & $\begin{array}{l}\text { Project partners } \\
\text { and invited experts } \\
\text { (UK based) }\end{array}$ & 22 & 14 \\
\cline { 2 - 5 } & $\begin{array}{l}\text { Focus of questions: A detailed set of questions about the online platform, } \\
\text { facilitation of the elicitation process, the credibility of the experts selected } \\
\text { and the results obtained and the project outcomes. }\end{array}$ \\
\hline
\end{tabular}




\begin{tabular}{|c|c|c|c|c|c|}
\hline \multirow[t]{2}{*}{$\begin{array}{l}\text { Quantifying Digital } \\
\text { Preservation Risk: } \\
\text { introducing a new } \\
\text { tool for decision } \\
\text { making (workshop } 1)^{3}\end{array}$} & $\begin{array}{l}\text { Workshop } \\
\text { (4 hours) }\end{array}$ & 16th June & $\begin{array}{l}\text { Digital } \\
\text { preservation } \\
\text { community (timed } \\
\text { for engagement in } \\
\text { Europe) }\end{array}$ & 30 & 11 \\
\hline & \multicolumn{5}{|c|}{$\begin{array}{l}\text { Focus of questions: Standard DPC event evaluation questions on satisfaction } \\
\text { with event, quality of speakers, online platform, followed by more specific } \\
\text { questions on the DiAGRAM tool and a focus on project outcome } 3 \text { - 'People } \\
\text { will have developed skills'. }\end{array}$} \\
\hline \multirow[t]{2}{*}{$\begin{array}{l}\text { Quantifying Digital } \\
\text { Preservation Risk: } \\
\text { introducing a new } \\
\text { tool for decision } \\
\text { making (workshop 2) }\end{array}$} & $\begin{array}{l}\text { Workshop } \\
\text { (4 hours) }\end{array}$ & 17th July & $\begin{array}{l}\text { Digital } \\
\text { preservation } \\
\text { community (timed } \\
\text { for engagement in } \\
\text { US and Canada) }\end{array}$ & 34 & 4 \\
\hline & \multicolumn{5}{|c|}{ Focus of questions: as above } \\
\hline \multirow[t]{2}{*}{$\begin{array}{l}\text { Quantifying Digital } \\
\text { Preservation Risk: } \\
\text { introducing a new } \\
\text { tool for decision } \\
\text { making (workshop } 3)^{5}\end{array}$} & $\begin{array}{l}\text { Workshop } \\
\text { (4 hours) }\end{array}$ & 27th July & $\begin{array}{l}\text { Digital } \\
\text { preservation } \\
\text { community (timed } \\
\text { for engagement in } \\
\text { Australasia) }\end{array}$ & 44 & 12 \\
\hline & \multicolumn{5}{|c|}{ Focus of questions: as above } \\
\hline \multirow[t]{2}{*}{$\begin{array}{l}\text { Quantifying Digital } \\
\text { Preservation Risk: the } \\
\text { story so far }\end{array}$} & $\begin{array}{l}\text { Webinar } \\
\text { (1 hour) }\end{array}$ & $\begin{array}{l}\text { 15th } \\
\text { October }\end{array}$ & $\begin{array}{l}\text { International } \\
\text { digital preservation } \\
\text { community }\end{array}$ & 58 & 6 \\
\hline & \multicolumn{5}{|c|}{$\begin{array}{l}\text { Focus of questions: Short set of questions asking whether attendees intend } \\
\text { to try out the DiAGRAM tool - if so, why, if not why? }\end{array}$} \\
\hline \multirow[t]{2}{*}{$\begin{array}{l}\text { End of project } \\
\text { celebration event }\end{array}$} & $\begin{array}{l}\text { Project } \\
\text { event } \\
\text { ( } 2.5 \text { hours) }\end{array}$ & $\begin{array}{l}\text { 8th } \\
\text { December }\end{array}$ & $\begin{array}{l}\text { Project partners } \\
\text { (UK based) }\end{array}$ & 20 & 4 \\
\hline & \multicolumn{5}{|c|}{$\begin{array}{l}\text { Focus of questions: Evaluation of the project outcomes with a deliberate } \\
\text { repetition of specific questions used in the elicitation event evaluation to } \\
\text { gather evidence of change of opinion over the course of the project. }\end{array}$} \\
\hline
\end{tabular}

Table 1 - project dissemination events for which feedback was gathered

\footnotetext{
${ }^{3}$ https://www.dpconline.org/events/past-events/quantifying-digital-preservation-risk-online-workshop

${ }^{4}$ https://www.dpconline.org/events/past-events/quantifying-digital-preservation-risk-online-workshop-2

${ }^{5} \mathrm{https} / / / \mathrm{www}$.dpconline.org/events/past-events/quantifying-digital-preservation-risk-online-workshop-3

${ }^{6}$ https://www.dpconline.org/events/past-events/quantifying-digital-preservation-risk-update
} 
* A count was not made of actual attendees at the workshops and webinars but it was noted that actual attendance levels were lower than the numbers signed up for the event. This was particularly the case for the second dissemination workshop on the 17th July, which also had a high dropout rate as the event progressed into the breakout sessions due to the late timing of the event for UK and European participants. The number of feedback forms received from this event was thus particularly low.

The DPC does not typically circulate feedback forms after a one-hour webinar, but decided to do so for the webinar on the 15th October as this was considered to be an additional opportunity to collect information that could inform the project evaluation. The low number of responses to this form is perhaps a reflection of the fact that the community is not keen to submit feedback for shorter events such as this.

The feedback forms included a mixture of qualitative and quantitative questions and these were tailored to the nature of the event and the audience. A brief summary of the types of questions is included in the table above, but it should be noted that specific consideration was given to the four project outcomes where appropriate.

Though the immediate goals of the project related more specifically to a UK audience, the move to online events necessitated by the pandemic gave the project team an opportunity to reach wider audiences. The timing of the three dissemination workshops was therefore staggered to optimize convenience for practitioners in different time zones. This approach proved very successful and has enhanced the likelihood of adoption. Countries represented at the three dissemination workshops included Australia, Brazil, USA, Canada, Germany, The Netherlands and Switzerland. It is hard to envisage any of these participating had the events been face-to-face as planned.

It should be noted that the feedback collected at the dissemination workshops in the summer referred to an earlier iteration of the tool. This feedback was shared with the project team and led to changes and updates, particularly regarding user interface enhancements. The feedback from these three workshops therefore reflects the status of the DiAGRAM tool at the time of the workshops, not at the end of the project.

\subsubsection{Interviews}

The DPC carried out a total of eight interviews with a range of stakeholders in this project (11 individuals in total). The interviews were carried out in January 2021 with a view to enhancing the data collected in feedback forms with a more detailed discussion about the project outputs and how the outcomes were met. Another key aim of the interviews was to ensure that an up-to-date picture was obtained.

As well as interviewing the project team and a key senior stakeholder at TNA, a call for volunteers to be interviewed was put out at the end of project event, and the three project partners representing a range of different types of archive were selected in this way. The DPC were also keen to have the perspective of stakeholders who weren't directly involved with the project but had attended workshops or tried out 
the tools. Staff at Library and Archives Canada and the Postal Museum were approached, and also agreed to be interviewed on this basis. Further details of the interviews can be found in the table below:

\begin{tabular}{|l|l|l|l|}
\hline Name and job title & Organization & Role played & Interview date \\
\hline $\begin{array}{l}\text { Tamara Thornhill } \\
\text { (Corporate Archivist) }\end{array}$ & $\begin{array}{l}\text { Transport for London } \\
\text { Corporate Archives }\end{array}$ & Project partner & 7th January \\
\hline $\begin{array}{l}\text { Heather Tompkins and } \\
\text { Angela Beking }\end{array}$ & $\begin{array}{l}\text { Library and Archives } \\
\text { Canada }\end{array}$ & $\begin{array}{l}\text { Digital preservation } \\
\text { community member }\end{array}$ & 7th January \\
\hline Helen Dafter (Archivist) & The Postal Museum & $\begin{array}{l}\text { Digital preservation } \\
\text { community member }\end{array}$ & 8th January \\
\hline $\begin{array}{l}\text { Heather Forbes (Head of } \\
\text { Archives Services) }\end{array}$ & $\begin{array}{l}\text { Gloucestershire County } \\
\text { Council }\end{array}$ & Project partner & 8th January \\
\hline $\begin{array}{l}\text { Jodie Double (Digital } \\
\text { Content and Copyright } \\
\text { Manager) }\end{array}$ & University of Leeds & Project partner & 8th January \\
\hline $\begin{array}{l}\text { Alex Green (Service Owner: } \\
\text { Digital Preservation), David } \\
\text { Underdown (Senior Digital } \\
\text { Archivist) and Hannah } \\
\begin{array}{l}\text { Merwood (Research } \\
\text { Assistant) }\end{array}\end{array}$ & The National Archives & Project team & 11th January \\
\hline $\begin{array}{l}\text { John Sheridan (Digital } \\
\text { Director) }\end{array}$ & The National Archives \\
\hline $\begin{array}{l}\text { Martine Barons (Director of } \\
\text { Risk Unit) }\end{array}$ & The University of Warwick & Project team & 19th January \\
stakeholder & 15th January \\
\hline
\end{tabular}

Table 2 - Details of interviews carried out for the project evaluation

The hour-long interviews were conducted online with two members of DPC staff, an interviewer and a note taker. Recordings were made (with permission of participants) so that interview notes could be enhanced and checked and quotes could be extracted as appropriate. A semi-structured approach was taken, with a list of key questions to ask but the flexibility to adapt as appropriate. At the beginning of each interview, the purpose of the meeting was explained and interviewees were encouraged to raise any additional points that were considered relevant to the project evaluation.

All interviews included a discussion around the four project outcomes. There was some variation in the other questions asked depending on the role of the interviewee. Whereas the project team were asked to reflect in greater depth on what went well and what they would do differently, the other 
stakeholders were encouraged to focus more on their use and intended use of the tool. Open ended questions were used to encourage flexibility and allow other ideas around the topics to emerge. A full list of interview questions can be found in Appendix 3.

A general inductive approach was used for qualitative analysis of the interviews to assess whether each of the four outcomes was achieved. This involved:

- reading the notes taken during the interviews for familiarization of the data to gain an understanding of the overall attitudes and accounts covered in the text;

- extracting and condensing texts into documents corresponding to each of the four outcomes;

- re-reading the text in those groupings for closer analysis to establish clear links between the summaries and areas of the logic model;

- using those links and findings to evaluate how the outcomes were met (in other words, linking the outcomes, activities and outputs that were most logically supported by the findings);

- subsequent readings to identify any emerging themes or areas, contradictory points of view, or unexpected insights to sufficiently present what worked well and why / what didn't and why). This approach allowed analysis to produce direct responses to the presented questions with room for other findings to emerge. The flexibility of the approach was well suited to the diverse contexts and priorities of those interviewed.

\subsubsection{Other sources of data}

Additional sources of data referred to in evaluating this project include other presentations and publications not mentioned in table 1 (Appendix 2), metrics such as website access statistics (Appendix 4), download statistics from articles on ResearchGate (Appendix 5), relevant Twitter statistics from the project team and corporate Twitter account (Appendix 6), and evidence of community validation assembled as part of the judging process for the Digital Preservation Awards (Appendix 7). This additional evidence available to view in the appendices and briefly referred to where appropriate in the text of this report. 


\section{Findings}

\subsection{Outcome 1: A wider range of people will be involved in heritage.}

Our digital heritage is at risk and it is recognized that future generations will not be able to access it unless it is effectively preserved and made accessible within a trusted digital archive. The 'Safeguarding the Nation's Digital Heritage' project and the DiAGRAM tool in particular will enable the preservation of heritage, but that is not the same as involvement in heritage. The question therefore arises: in what ways has the 'Safeguarding the Nation's Digital Heritage' project and the DiAGRAM tool involved a wider range of people in heritage?

Digital preservation is path dependent. The work that is carried out in memory institutions today will undoubtedly impact the quality, quantity and condition of the digital heritage that is available for future audiences. If good decisions are made about how to manage this heritage, it follows that future audiences will be better able to access what they need, becoming more involved in heritage through their use of the digital archives. Equally, if poor decisions are made, or difficult decisions are deferred, then it is likely that access to the digital heritage will be degraded. Moreover, it follows that if these decisions are more closely and expertly assessed, management becomes more transparent with respect to stakeholders and accountable with respect to policy owners.

The evaluation of this outcome is thus quite closely tied to the second outcome: 'Heritage will be in better condition'. The project aimed to create a decision-making tool that would help the archives sector to understand and quantify risks to the digital heritage and thus make better and more impactful decisions. If this aim is realized, it then follows that there is a greater likelihood that the fragile digital archives in our care are better preserved and available for wider use. In the confines of a short project such as this, it is not possible to thoroughly evaluate this assumption since the benefits will be deferred, potentially by several decades. However, it is certainly the case that evidence collected from interviews supports this claim.

The main audience of this project as it was conceived was the archives sector in the UK: the pandemic allowed this to be expanded to the English-speaking world. The intention of the work was to build a tool to help archivists make important decisions about how to manage and mitigate the risks to our digital heritage. The project partners and experts that were drawn together to form the elicitation panel consisted of representatives from a range of different types of organizations within the archives sector. The dissemination events organized as part of the project were aimed at an audience of archivists and others involved in digital heritage. Aiming the events at these audiences was an important strategy in realizing outcome two: 'Heritage will be in better condition'. Of the audiences already involved in heritage, some will have not been specifically involved with digital preservation before, so this project will have expanded their knowledge in this important area. However, there is also evidence that other audiences have been reached through this project, including those who had not previously been involved in heritage. 
Alongside the planned dissemination events and workshops run with the DPC, an impressive range of other communications were employed by the project team with presentations and publications through a variety of different channels. As can be seen from the list of dissemination activities (Appendix 2), a large proportion of these events were aimed at the heritage sector to audiences of archivists and those already involved with digital preservation activities, but some targeted new audiences. For example, a short article written for the IRMS Bulletin will have been read by an audience of records managers, some of whom will not have previously been involved in heritage. Some of the events with an audience of 'researchers' certainly will have included individuals who had not been involved in heritage before. In particular, a presentation at the Warwick Partnership Event was aimed at an audience outside of the heritage sector, and the digital heritage theme will have been a new topic for the attendees. Several dissemination activities were aimed at Government Analysts, with two presentations and a blog post delivered over the course of the project. This again provided a new audience not previously involved in digital heritage, and it is hoped that they may be able to put this learning to practical use as they create digital content today that will become the digital heritage of the future.

Additional evidence that came out strongly in the interviews relates to new internal audiences who will gain a greater understanding of heritage through an organization's use of the project outputs. Several interviewees discussed how the DiAGRAM tool could be used to communicate more effectively with key internal stakeholders. Colleagues working in ICT departments and senior managers were specifically mentioned. By providing a visual graphical output on risks to digital heritage, DiAGRAM is a communication tool for heritage professionals, helping them to illustrate their arguments clearly and effectively, making the case for putting appropriate mitigations in place. One interviewee talked about how her use of the tool would necessitate conversations with colleagues in IT in order to answer some of the questions required to use the tool:

"A lot of them were things I should know but I needed to do a bit of information gathering which is actually going to be really useful, not just in terms of the risk assessment but just having a far better handle on a lot of the things. I highlighted the bits that either I had no idea of the answers or I thought I knew but I wanted to double check and that was kind of more of the technical IT systems side of it. I raised a job with our IT team to kind of talk through those and we had a meeting, talked through those and then I input it all into the tool in one go."

\section{Helen Dafter, The Postal Museum}

Several interviewees touched on the fact that digital preservation risk can be hard to articulate to colleagues that are not directly involved in digital heritage. Though the archivist may have an idea of what actions to take to mitigate risk, it can be hard to get necessary buy-in from colleagues in other departments or to budget holders. The DiAGRAM tool provides a visual and graphical output that can be easily shared with internal stakeholders and it is anticipated that this will be a great help in increasing their understanding of digital heritage and making the case for action. A point was clearly made by more than one interviewee that using DiAGRAM with these internal stakeholders will provide credibility and evidence to their arguments. 
Finally, the project also promised to build a collaboration between the heritage sector and statisticians and it is clear that the cross-disciplinary nature of this project has brought heritage to new audiences. Although the Bayesian methodologies employed by the partners are well established, this is likely the first time that they have been deployed within the context of digital heritage and none of the subject experts have previously worked in archives. Though just a small number of people, the impact of this partnership can be seen to have greater potential. It was certainly clear from interviews with the project representative from The University of Warwick that the ripples from the project may continue to spread to new audiences for some time to come, both through the project becoming a useful case study to share during future public engagement events, and as a continuing challenge for future statistics students to develop further over the next few years. One such event has been scheduled for $23^{\text {rd }}$ March $2021^{7}$

"This could turn into a very nice talk for me because people will really be interested in the problem and it's quite a relatable problem. We've all had software that has gone redundant and we can't look at our photos anymore [...] or films from childhood because they are on a Betamax tape and we haven't got a machine anymore. [...] if you are talking at school level or general public level, that mathematical sciences has an important part to play in British culture [...] then it is a nice example."

\section{Martine Barons, The University of Warwick}

\subsection{Outcome 2: Heritage will be in better condition.}

Rich, complex and fragile, our digital heritage exists in a rapidly evolving risk environment and faces many different threats. These include the technological risks which we most readily associate with digital records, but also encompass policy, environmental and human factors which the archives sector has been slower to recognize. Are digital archives in better condition because of the project and is that improvement likely to be sustained?

Digital preservation is seen as a technically complex and costly undertaking, which is not accessible to the majority of those that are responsible for digital archives. A lack of understanding of the interplay between different risks to digital archives can be seen as a barrier to managing these archives effectively. An understanding of the risk landscape is therefore an important step in enabling heritage organizations to better preserve digital heritage for future generations.

This project aimed to better understand risks to digital heritage and to communicate those risks to the wider archives sector. The project wanted to step beyond just articulating those risks to the community, and planned to encapsulate the knowledge gathered in a tool which could be used by those managing digital heritage to make better informed decisions about how to preserve archives for the long term, considering where limited resources should be placed in order to have the greatest impact.

\footnotetext{
${ }^{7}$ Mathematics for safeguarding the nation's digital memory - IMA
} 
It can be assumed that when an archivist uses the DiAGRAM tool to inform their decision making about digital preservation, those decisions made and enacted will lead to heritage being in better condition. By mitigating risks to digital archives, archives will be preserving them better, leading to improved longerterm outcomes.

Not only can we surmise that the tool leads to better decisions, but also that it leads to decisions that are well informed and backed up with evidence. So, as well as helping with the decision-making process, the tool also offers credibility and authority to those decisions; thus, it should lead more frequently to buy-in from managers and budget holders. Making an effective case for investment or changing practices can be a challenging area for those working in the archives sector as evidenced in the interviews.

Evaluation of this outcome therefore addresses the following questions:

1. Has the project improved understanding of digital preservation risk across the sector?

2. Are people using the tool for evidence-based decision making to manage the risk to digital heritage?

3. Does using the tool give authority and credibility to decisions, leading to a greater chance of those decisions being enacted?

As with outcome one, the time frames within which evidence of this can be seen are much longer than the time we have available to carry out this project evaluation. Not only does it take time to change the working practices of archivists, bringing new tools into their standard ways of working, but the real impact of decisions made now may not be felt immediately. Archivists take a long-term view of preservation, considering the impact their actions today have much further down the line. With that in mind, the evaluation has focused on the more measurable and immediate outcomes that can be evidenced at this point in time.

\section{Improving understanding of digital preservation risk}

As is evidenced in outcome three, one of the ways in which people have developed skills is through an increased understanding of digital preservation risk. This was noted by many of those who have been involved in the project and is evidenced by feedback from the expert elicitation process, workshops and through the interviews that were conducted. Even if participants do not go away and use the tool itself, this increased understanding will lead to better outcomes for digital heritage if used to inform decision making in a more informal or ad hoc way.

Taking this point a little further, one interviewee noted how useful it was just to download the questions that are used within the DiAGRAM tool and work through them, using them as a basis for conversations with colleagues and understanding the current situation. Another interviewee talked about a shift towards a risk-aware way of thinking which clearly will have positive impacts regardless of whether the tool itself is used. 
"So already for TNA, having the model has changed how we think both in a how we reason kind of way but also culturally, it has shifted our focus from tooling and the centre of our universe being the system, to risk and the centre of universe being how we manage risk."

\section{John Sheridan, The National Archives}

\section{Use of the tool for evidence-based decision-making}

As changing working practices takes time in this sector, it was not envisaged that we would have evidence that the DiAGRAM tool was widely adopted on completion of this project. We were however hoping to see one or two case studies of the tool in active use and indications that others across the community were investigating the tool or intending on using it in the future.

Evidence on the use and intended use of the tool was collected primarily through interviews and more informally through the DPC's wider community engagement role. TNA reported that they have already used DiAGRAM to inform and evidence their spending review and achieved a very positive outcome from doing so. The project team have reported that this result alone is reason enough to commit to continuing support and development of the tool going forward. This particular use case is further discussed under outcome four.

Other interviewees talked about their use or proposed use of the tool. Some had already modelled their current situation using the tool and were considering how they could move forward and model other scenarios over the next few months. Some discussed its use to look at a particular type of content, for example web archives or audiovisual collections. Others already had more concrete plans, for example to use the tool to help make a business case for investment in digital preservation and planned to make a start on this over the next month.

It was also observed from the DPC's wider role within the digital preservation community that others are starting to explore use of the DiAGRAM tool. As well as being used to assess risk to content held within an EDRMS ${ }^{8}$ by two members of the DPC's EDRMS preservation task force the DPC is aware of two others within the wider community who are exploring the use of this tool to inform their digital preservation work.

Clear evidence of an intention to use the DiAGRAM tool in the future was also collected via feedback forms for the three dissemination workshops (see Figure 1).

\footnotetext{
${ }^{8}$ Electronic Document and Records Management System
} 
How likely is it that you would use the DiAGRAM tool to support your digital preservation decision making in the future?

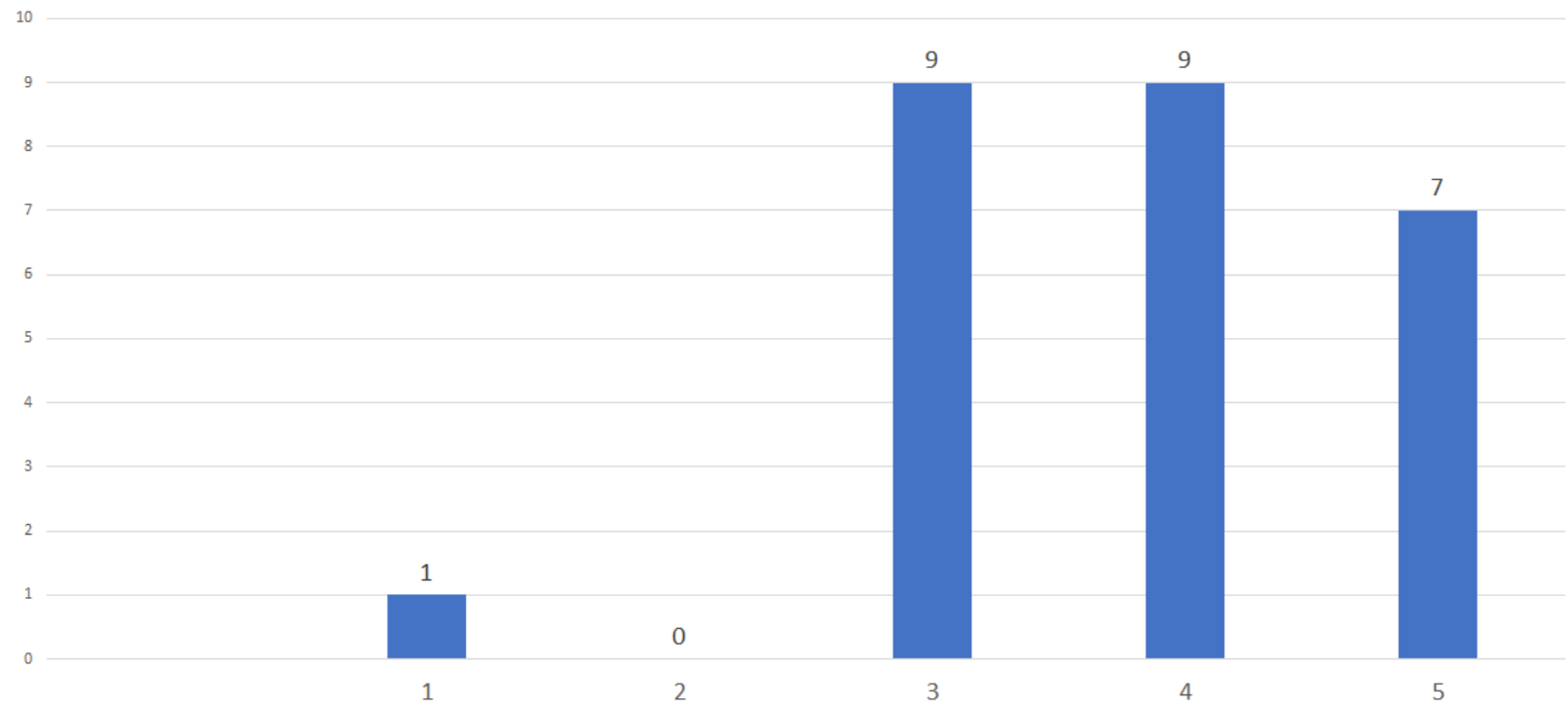

Figure 1 - Responses to question 'How likely is it that you would use the DiAGRAM tool to support your digital preservation decision making in the future?' from DPC dissemination workshops, Summer 2020. (1 = very unlikely, 5 = very likely)

It should be noted that the respondent who selected a score of 1 for this question mentioned in their comments within the feedback form that they have selected 'very unlikely' because they work in education rather than within an archive.

Further qualitative evidence was given by some attendees on how they intended to try out the tool. Selected responses in answer to the question "Is there anything you will do (differently) as a result of attending this event?" are listed below:

- "I'm going to talk to colleagues about this and see if we can find a way to use the tool to help with our decision making."

- "I'll try to draw the actual scenario in my institution, although it may seem difficult to specify some metrics, and do some analyses on my own. Even so, l'll try to use it for advocating about digital presentation and presenting first steps to take in order to leave the "doing nothing" status."

- "I will share the tool with colleagues and try it out with proper data. In particular, I will look at the comparison section, to identify key steps which could reduce our risk."

- "Definitely keep an eye on the development of the tool with a view to integrating it within the decision process within our organization."

- "I might include this as one of the ways I present risk and try to present the potential impact of changes to policy and practice." 


\section{Using the tool for effective communication}

The benefit of DiAGRAM as an effective communication and advocacy tool was a theme that came out very strongly in the interviews. Firstly, it was noted that it was an effective communication tool to use with colleagues that are not directly engaged with digital heritage (see evaluation for outcome 1). Secondly, it was reported that the tool output gave credibility and authority to their decisions. This was seen to be a key factor in helping to make the case for action to mitigate risks to their digital content.

Several interviewees mentioned that colleagues had not previously wanted to simply take their word for it if they were proposing a particular course of action. They felt that being able to demonstrate evidence-based decision-making using output and visualizations from the DiAGRAM tool to back up a proposal would increase the chances of their request being accepted, particularly given it was created by a sector leader such as TNA. The assumption is made that heritage will be in better condition as a result, with decisions on how to preserve heritage being enacted because of the evidence base the tool is built on and authority that this brings.

"This was really interesting to me to learn about this is how the model is built and how it is informed, the diversity of opinion, de-centralization aggregation, independence...

...to me, these are the building blocks that lend a credibility for this to be a tool you can trust and I think that this is one of the biggest things in the field; to establish a trust about how this content can be handled. What is the risk we are taking on in terms of preserving it and what we can operationally do right now?"

\section{Heather Tompkins, Library and Archives Canada}

"Because it's a model that's feeding in so many different elements, you can really start to visualize. Ok, what happens if we focus a resource in this area? What happens if you take this away from me? This is how it affects everything else. Because as I said before, I very much feel for a lot of archivists, we can stand there and say this stuff to our funders until we are blue in the face but for some reason to a certain extent they either don't believe us or feel that it is easy to fob us off whereas if we have this concrete evidence and tool behind us it becomes much, much more difficult to do that."

\section{Tamara Thornhill, Transport for London}

\subsection{Outcome 3: People will have developed skills.}

In the project bid, this outcome was articulated as the transfer of skills in data and risk analysis, statistical modelling and expert elicitation from specialists to digital archivists and the wider UK digital archives community. It was expected that participants in the project would gain a better understanding of digital preservation risks, acquire new analytical skills, and employ what was learned to assess risk at their organization. It was also noted that the process of co-creation of the model with a range of project partners from across the archives sector would allow heritage professionals to contribute actively and share their domain expertise with one another, enabling all to benefit from the collective expertise of the community. This was particularly important as the logic model suggested that a 'Not Made Here 
Syndrome' could be a barrier to impact especially given the innovation involved and the uniqueness of TNA. The project therefore was required to engage a large group to be credible. If it failed to do this then the outcomes would be significantly reduced. The question therefore arises: have sufficient people been involved to ensure that the tool is credible and of relevance beyond the funded organization?

In contrast to outcomes 1 and 2, the time frame within which evidence of this outcome can be seen is shorter, though it is anticipated that longer term impacts will also continue to be felt over time. Evaluation of this outcome focuses on measurable and immediate outcomes expressed by the project team, project partners and workshop participants.

Responses to the interview question around skills development were very positive across the board, with all respondents able to articulate at least one new skill that they had developed as a result of involvement in this project. Feedback forms from dissemination events also included a question about skills development and produced another body of evidence that is referenced in this section.

Perhaps the most obvious transfer of skills and knowledge are those which relate to the crossdisciplinary nature of this project.

"It was an incredibly challenging project and pushed us outside of our comfort zones into areas that we were not expecting at the outset of the project document... It was a completely different field [statistics and Bayesian Networks] giving insight into this field of research in addition to learning from and sharing experience with experts across the archives community." Jodie Double, University of Leeds

Firstly, there is much evidence that the digital heritage community has developed new skills and knowledge relating to statistics and the methodologies used for expert elicitation. Several interviewees touched on this. For some this was a completely new area, though others had a more mathematical background and enjoyed the opportunity to refresh and build on prior knowledge.

"I studied statistics in my undergrad and hadn't thought about it in a meaningful way in ages. I think it was nice to sort of dust off and think about that as a skillset that could apply more directly to digital preservation and archives. We think about talking in percentages and talking about what we know we can preserve, and we have confidence in but to actually layer that with a statistical model - that got me quite excited as a former 'math nerd.'"

\section{Angela Beking, Library and Archives Canada}

Other interviewees were slightly daunted by the statistical element of the project but still felt they now benefitted from a greater understanding of how these techniques can be used to benefit the archives community.

Feedback received from the dissemination workshops in response to the question "Has this workshop given you any new knowledge or skills?" follows on from this theme: 
- "Maths is really not my area, but I now have a vague understanding of what Bayesian networks are!"

- "Bayesian network was new for me. Also was interesting to have a structured list of risks and links between them."

- "Slightly(!) increased understanding of the math/science behind risk management approaches"

For some attendees of the dissemination workshops, it was noted that the level of detail on the statistical techniques was greater than required. A few comments were received in response to the questions "Was there anything else that you would have liked us to have included?" and "Any other questions and comments?" which suggested that too much time was given to presentations on the statistical methodology used, but note that feedback was reviewed after the first workshop and some adjustments made for future events:

- "I think the Introduction to the statistical methodology would be improved by simplifying things and use digital preservation examples."

- "Not really. For me there was almost too much about the model development. The amount of math intimidated me."

- "I personally didn't really need the level of detail about how the model works but understand that there were people who would have been very interested."

It was also clear that the elicitation techniques employed by the project team to inform the statistical model was a new area to many and this was mentioned by some in relation to new skills. In interview, the project team from TNA discussed their new awareness and understanding of elicitation techniques and in particular how to avoid bias. It is clear this technique could be applied usefully in other digital heritage contexts.

The success of this initial collaboration between digital heritage professionals and statisticians is clear and has potential to open the door to future cross-disciplinary research and this point was also articulated in interview with the project team.

"Two years ago I would have sworn that mathematical techniques had no relevance to archival practice but this project has amply demonstrated that they can have a direct, practical application. This has to open the door to other potential collaborations and not only with the world of maths. So let's see what else is out there that could help us tackle the manifold challenges we face in digital archives."

\section{Alex Green, The National Archives}

Anecdotal evidence has been gathered after the fact also that the project team has brought knowledge of the tool into discussions around statistical modelling including in the Home Office and in the Department for Digital Culture media and Sport; and also around the production of the 'BitList', the Global List of Digitally Endangered Species. ${ }^{9}$

\footnotetext{
${ }^{9}$ http://doi.org/10.7207/DPCBitList20-01
} 
On the other side of this cross-disciplinary knowledge exchange were skills relating to the preservation of digital heritage that were passed on to members of the project team who had not previously been involved in this field. This point has already been touched on under discussion of outcome 1. Two members of the project team who were interviewed talked about their own development of skills in this area, discussing how this is directly influencing their own digital working practices, and how this new knowledge is being spread further through their personal and professional networks.

Additional skills developed during the project, in particular by the project team at TNA, included technical skills such as software development for the web. Other existing skills sets were further developed and enhanced over the course of the project, including communication, online presentation and writing skills.

Moving into a discussion of skills developed by the wider community as a result of this project, feedback from the dissemination workshops gives a clear indication that the project has resulted in a better understanding of digital preservation risks. This is evidenced by Figure 2 and in further answers to the question "Has this workshop given you any new knowledge or skills?" as listed below:

- "To visualize the relationship between the variables and how it affects the outcomes of digital preservation."

- "It has given me a new framework in which to consider the various risks affecting digital preservation"

- "Yes. It helps think of which types of risk affect which parts of the digital preservation puzzle."

- "Different way of approaching risk and "what if" scenarios to communicate to leadership."

- "I would say this gives me a new way to present risk assessment and the potential impact of policy changes."

After attending this workshop and using the DiAGRAM tool, do you feel you have a greater understanding of the complex digital archiving risk landscape and of the interplay between digital preservation risk factors?

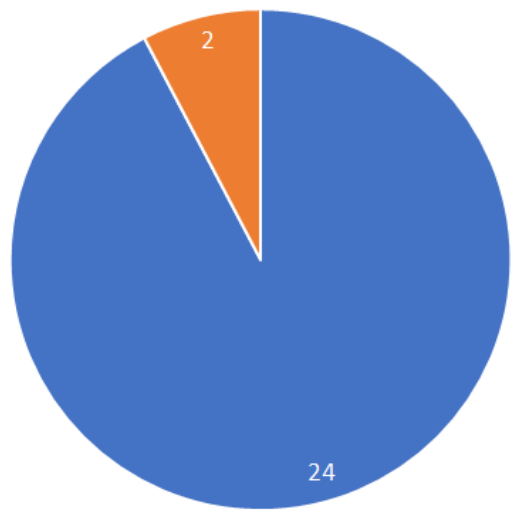

- Yes $\mathbf{n o}$ 
Figure 2 - Feedback from the 3 dissemination workshops in answer to the question "After attending this workshop and using the DIAGRAM tool, do you feel you have a greater understanding of the complex digital archiving risk landscape and of the interplay between digital preservation risk factors?"

As well as understanding digital preservation risk, it is clear that further skills have been developed around advocacy, in communication of risks to colleagues, in particular to senior managers. This was a theme that was mentioned in several interviews as well as in event feedback.

In addition to the formal feedback two agencies have been in touch after the data gathering phase of the evaluation to confirm that they have a process in place to deploy the tool in earnest. One of these is a local authority archive, the other a large research data centre with preservation responsibilities. Although anecdotal, this is important evidence that the project has begun to move from short term outcomes towards the more mature medium term outcomes escribed in the evaluation logic model.

The clear outcome in terms of skills addresses the core concern that the project's main outputs are credible in the eyes of a wide digital preservation community. The project team worked in an exemplary and innovative way to involve participants from around the world, an opportunity which only became apparent in the light of the pandemic. This is most evident in Table one which demonstrates the very large number of individuals and countries which were able to contribute to the project, and in the evaluation forms at the end of the workshops (Figures 4, 5 and 6 below) which asked participants if the resulting tools would be useful, if the participants at the elicitation event had sufficient knowledge, and if the results were credible. It is also implied in feedback received about adaptations to the tool which were made in response to the feedback from the first round of online workshops.

\subsection{Outcome 4: The funded organization will be more resilient.}

The project aimed to improve the capacity of the partners to understand and explain the ever-shifting threats to digital heritage. If successful, this improved capacity should result in greater resilience for the partners, enabling them to better address and withstand those risks. In this context resilience is not simply about mapping risks but also responding to them and being able to demonstrate change.

There are two funded partners in this project so any analysis of this outcome should focus on impacts within these two organizations. However, a wider range of unfunded project partners were also involved in the project and impacts may also have been felt within these organizations. This assessment of resilience therefore looks at all of these aspects. However, the core research question most relevant to the evaluation is: Is The National Archives more resilient because of the project and in what ways?

An important and immediate outcome from the project for TNA has been the successful use of the DiAGRAM tool to inform their submission to the recent UK government spending review. Using the tool internally to articulate risks to digital heritage and successfully make the case to the Treasury for the investment needed is an impressive achievement and direct evidence that the organization is more resilient as a result of this work. The project team are delighted with this outcome and will be able to 
expand their digital preservation team as a direct result. Given this success, the team intend to use the DiAGRAM tool to inform future spending reviews and continue to build up resilience within their organization.

"[...] it's not been like an academic project, it's been archivists building a model for archivists and those archivists are also people who are involved in digital preservation and decision making every day, I think it has made a difference already for us and it's incredibly early days" John Sheridan, The National Archives

An additional benefit for TNA has been reputational. The project has allowed TNA the opportunity to show case its work internationally, and with partners on a large scale on a sustained initiative of ubiquitous importance and wide benefit. In so doing TNA's brand has been enhanced. This is hard to quantify but clearly expressed in citation at the Digital Preservation Awards:

“Once again UK TNA's thinking is a level higher than the rest of the DP community; once again their leadership means we'll all be a level up soon too."

Digital Preservation Awards 2020

For the academic partner at the University of Warwick organizational resilience is measured in different way. A successful project such as this will have research impact (typically measured through the Research Excellence Framework) and will raise the profile and enhance the reputation of the department. The project also clearly demonstrates their ability to work in different sectors and the suitability of their statistical methods to translate into a different context. This could lead to further cross-disciplinary collaborations in the future. For example, the project has led to an invited presentation scheduled with the Institute of Mathematics raising the profile of the University and its research capability among peers ${ }^{10}$. All of these factors lead to an increase in resilience for the Applied Statistics and Risk Unit at the University of Warwick.

On interviewing the wider project partners, it was clear that though some felt it was too early to tell whether they were more resilient as a result of the project (having not yet used the tool to inform their own decision making), one interviewee felt that partners will also become more resilient as a direct result of their involvement with the project:

"I think those of us who are partners should be more resilient as well because we've got a wider network of contacts...you can't do these sorts of things alone... it's easier to progress them collaboratively. I'm planning to use the tool to move on digital preservation and make our organization more resilient. It's absolutely critical we deal with this for our future sustainability." Heather Forbes, Gloucestershire County Council

\footnotetext{
${ }^{10}$ https://ima.org.uk/16319/mathematics-for-safeguarding-the-nations-digital-memory/
} 
Lastly it should be mentioned that as a UK sector leader for archives, the activities of The National Archives typically have a greater impact across the sector. As other archives become aware of the project and start to bring the new tool that has been developed into their own workflows, there is a strong likelihood that the ripples from this project will be more widely felt and that other archives in the UK will become more resilient as a result of better-informed risk-based decision making supported by the DiAGRAM tool.

\subsection{What worked well?}

In any evaluation, as well as looking at whether specific outcomes were met it is also useful to reflect more broadly on what went well. This question was specifically asked in the interviews and in the event feedback and this section draws on responses given and in some cases on observations made by the DPC throughout the project.

It is clear that the project team felt that they had achieved more than they set out to achieve. The project bid itself mentioned the creation of a tool for evidence-based decision making but there was little detail on what this might look like and no preconceptions. A crude command line tool could have been developed but instead the project team have created something much more impressive, going further than they initially anticipated. One of the project partners stated in interview that "the front end and the website that's been produced are excellent. More than I expected". Another project partner described the tool as "intuitive and infinitely flexible".

The iterative development of the tool over the course of the project was also encouraging to see. A huge amount of feedback was provided to the project team during the three DPC dissemination workshops in the Summer of 2020 and it was clear that much work was carried out as a result of the feedback and further user testing, leading to a much-improved tool. One interviewee specifically mentioned the improvements over the course of the project, saying she found one of the earlier versions of the tool a little confusing but the new version much easier to use.

Another point coming from the interviews was how the project team responded to and adapted to the pandemic. From March 2020 face-to-face meetings and events were no longer possible and all project activities were carried out online. The online dissemination activities necessitated by the lockdown and other restrictions did not have so many expenses associated with them, so funds for planned face-toface events were effectively redistributed and used for further development of the user interface of the DiAGRAM tool. The project team reflected in interview how valuable this additional work proved to be and noted that if they were to run a project of this kind in the future, they would build in additional resource for user interface development from the offset.

The project team adapted well to the challenges brought by the global pandemic and this brought some added benefits, such as the ability to disseminate their work to a wider and more international audience. The three dissemination workshops specifically took advantage of this by staggering the times of the meetings to enable attendees from different time zones to take part. It is clear the project had greater international reach because of the pandemic. 
One of the most important project activities was the expert elicitation panel event. One of the project partners mentioned that they had been unsure how this would work as an online process but came out of this workshop happy that it had worked just as well as a face-to-face process. In interview it was mentioned that there were some benefits to online expert elicitation, in particular the ability to more closely control and moderate the group.

The evaluation forms gathered from the online elicitation workshop in April 2020 were broadly very positive and for the most part reflected this view that online elicitation had been a good experience. This was particularly encouraging given the timing of this workshop only a few weeks from the start of the UK lockdown, when participants were less familiar with online ways of working.

Selected answers to the question "Is there anything else you would like to say about the workshop?" give a sense of how well this event worked from the perspective of the project partners:

- "I was initially worried that it would be difficult attending via Zoom, but I felt involved and engaged throughout."

- "I think it was transferred to the online environment very well."

- "Very well organized, paced, and delivered - especially given the change in circumstances and delivery method necessitated by Covid-19."

- "Workshop was fascination [sic], I very much enjoyed participating. The logistics worked well, even under Coronavirus lockdown."

- "Strange experience for all but I thought that the TNA team and Warwick did a good job of trying to shepherd everyone through the two days."

The community aspects of the project were also considered to be very effective. The project team reflected on the fact that they could have carried out this piece of work on their own, but the inclusion of a range of project partners representing the wider sector made the outputs more broadly applicable outside of the unique context of TNA.

The project communications are also worth noting in this section. A couple of the project partners mentioned specifically how well the project team communicated with them. A regular online newsletter was circulated which briefly and effectively kept all partners informed on progress and plans.

"The communication from the project team was exemplary at all stages." end of event feedback form

The project team also reported that it was hugely beneficial to be working with the DPC, both for the organization and hosting of events, access to the wider international digital preservation community and for ideas and feedback during the project. Good feedback was received in the evaluation forms for the DPC workshops and some examples are presented below:

Selected answers to the question 'What did we do well?' for the dissemination workshops: 
- "I liked very much the online demo of the tool and the breakout rooms where we were able to try the tool hands on and give immediate feedback."

- "Really useful balance of theory and practical. And all delivered in a friendly and light manner."

- "Very professional, welcoming, clear-spoken, informative, and well organized."

- "I think you made a compelling workshop even though a webinar was not your medium of choice. I think the breakout sessions worked quite well."

- "small groups in the breakout rooms encouraged participation - so it did feel like a workshop and not a webinar"

- "DPC team is always an excellent host. Thank you for opening this workshop for non-members."

As well as these DPC-hosted events, considerable effort went into disseminating the DiAGRAM tool to the wider digital preservation community. There is limited benefit in developing knowledge, tools and resources without disseminating this information to those who may benefit from it. As is evidenced in Appendix 2, a wide range of dissemination activities were carried out beyond the events noted in the methodology section of this report. This is further backed up with details of website access statistics (Appendix 4), ResearchGate download statistics (Appendix 5) and Twitter impressions (Appendix 6). All of this information paints a strong picture of project dissemination through a variety of different channels. The importance of this dissemination to achieving many of the outcomes set out was clearly recognized by the project team and acted upon.

In parallel to and complementing this dissemination work, was the selection of the project as a finalist for The Software Sustainability Institute Award for Research and Innovation in the 2020 Digital Preservation Awards ${ }^{11}$. As well as being a considerable achievement given the high standard of applications received, the awards process itself facilitated wider awareness and engagement with the project internationally. The judging process of the Digital Preservation Awards collected and incorporated feedback from DPC Members (Appendix 7) and demonstrated further the high regard with which this project was held by the wider digital preservation community.

"Very strong, convincing and as far as I can tell entirely new basis for executives to understand the provision of funding, policy and priority to investment in digital preservation, as well as the practical outcomes of preservation actions. This is a step change from anything that has come before."

\section{Selected feedback from Digital Preservation Awards}

The profile of the project was raised once again within the digital preservation community through its self-nomination for the 2020 NDSA Innovation Awards which once again, provided an opportunity to talk about the project to an international audience.

\footnotetext{
${ }^{11}$ https://www.dpconline.org/events/digital-preservation-awards/the-finalists//events/digital-preservationawards/dpa2020-finalists-r-i
} 


\subsection{Areas for improvement}

Any project evaluation must also reflect on things that didn't work so well and consider both lessons learned and improvements that could be made for the future. Questions in interviews and evaluation forms were designed to draw out some constructive feedback to help inform this section of the report. This section has three parts covering:

1. Feedback from the digital preservation community on the project and its outputs

2. Feedback from the elicitation process

3. Lessons learned

\section{Feedback from the digital preservation community on the project and its outputs}

Though all interviewees were very positive about the project and the DiAGRAM tool, there was some useful feedback gathered on barriers to adopting the tool and aspects that could be improved.

The need for case studies showing how the tool can be used was discussed in several interviews. One interviewee mentioned that in order to make the tool easy for others to use, it needs to be as straightforward as possible. Case studies will help potential users understand what the tool is for and how it can help them.

Alongside case studies, another useful addition to the tool mentioned by interviewees would be benchmarking information from other organizations. This will help users of the tool interpret their own results and move the rather abstract percentages into something more directly relatable. For example, an organization may model their current scenario and find the tool gives them a score of $60 \%$.

Benchmarking information from other organizations would help them to better understand whether $60 \%$ was a score they were comfortable with or whether action to mitigate some of that risk should be taken. ${ }^{12}$

One interviewee highlighted two risks that are not currently addressed in the DiAGRAM tool. First the risk of an archive not getting hold of the digital content in the first place, and second the risk associated with disorderly exit of the supplier. It may be the case that these risks are out of scope for the DiAGRAM tool, but if this is the case it would be useful to consider how the scope of the tool is communicated to users.

There were some challenges noted by interviewees around finding the right data to input into the model. Some mentioned that the results of the tool are only of value if you have put the right data into it, and getting the right data is not always a simple process.

This was also noted from feedback collected during the dissemination workshops. Answers to the question "How easy was it to find the relevant information to input into the DiAGRAM tool?" as

\footnotetext{
12 Communication after the end of the evaluation confirms that two reference models have since been added in response to this feedback.
} 
illustrated in Figure 3 show that this may be a challenge for some. Note that these scores were lower than the answer to the question "How easy was it to use the DiAGRAM tool?", which scored very highly.

How easy was it to find the relevant information to input into the DiAGRAM tool?

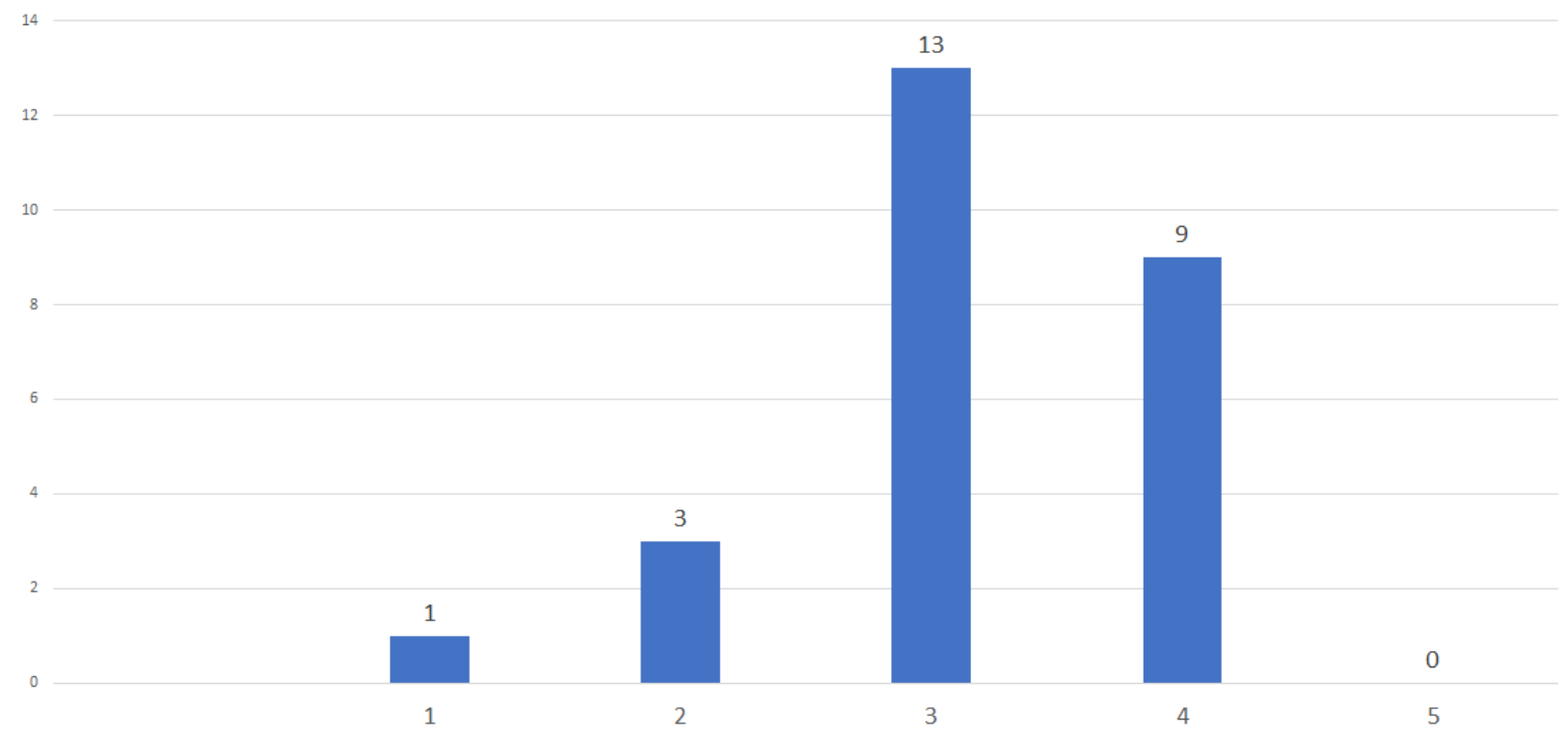

Figure 3 - Graph showing answers to the question 'How easy was it to find the relevant information to input into the DiAGRAM tool?' from the dissemination workshops.

Relevant feedback noted in answer to the question "What barriers might prevent colleagues from using the DiAGRAM tool?" from the end of project event evaluation form is also copied below:

- "I can see a number of issues for other people/organizations including the steep learning curve to get started (e.g. familiarity with NDSA, being able to make meaningful estimates to some of the questions) and accurately interpreting the results and scenarios"

Finally, one interviewee talked about specific governance issues at their institution that made the tool difficult to use. In an organization where not all of the variables referenced within the tool are owned and controlled by one team, there is work that needs to be done to get buy-in and agreement from colleagues across departments for using the tool. Without this cross-departmental engagement, the tool cannot be used, as coordination and cooperation are needed in order to model the current scenario and consider how to reduce risk. One of the interviewees was interested in finding out how to leverage the tool internally within a complex and hierarchical governance structure where roles and responsibilities for digital preservation are distributed. Though these barriers relate specifically to the structure and ways of working of the organization in question, it may be useful for the project team to take note of this as a potential barrier and consider whether this is something that could be addressed in advice and guidance for users or in the configuration of the tool. 


\section{Feedback from the elicitation process}

Feedback collected from the experts who participated in the online elicitation process was broadly positive, but it is worthwhile noting in this section some reservations that attendees had, both about the translation to an online platform and the value of the results that were produced by the process. Selected feedback is provided below and should be balanced with comments listed in the 'What went well?' section above:

The following comments from the expert elicitation workshop evaluation form were in answer to the question "Is there anything else you would like to say about the workshop?":

- "The scores for comments, questions, discussion and feedback are low not because of the organizers. The meeting was run really well and everyone was encouraged to input. Some comments were lost in the chat and not addressed. I think how comfortable or confident you feel participating depends very much on the quality of technology you have available which puts some members at an immediate disadvantage. Introductions and familiarity that a face-to-face group workshop would allow for could not be present and as some members of the group already knew each other this made it slightly isolating. This is not a comment on the organization or the welcoming aspect of the participants. It is a comment on how this technology disadvantages some people more than others and it is a lot harder to be confident online with a group that you do not know. For example it was hard to argue a point once someone had disagreed with it, even if they had interpreted what you said wrongly."

- "My scores make allowance for using Zoom which although it made it possible it was only a partial substitute for a face-to-face interaction."

Further comments from the expert elicitation workshop evaluation form were in answer to the question "Any other comments on the elicitation methodology?":

- "I was uncertain about how effective some of the questions and also about the definitions used."

- "I understand that it's very hard to structure questions to be generic when talking about various media and different scenarios with so many variables, but I found some of the questions a bit abstract."

- "The methodology was new to me - I can see the logic behind it. I felt some questions didn't uniquely focus on digital preservation risks/challenges, and I don't understand whether this was deliberate. Or whether it matters. Specific examples that spring to mind are the question about flooding in an archive strongroom, and knowledge of conditions of use of a file. My instinct is that if we're trying to identify risks to digital files, these should specific and outside/additional to the risks to archives in general."

- "The methodology is fine. My concerns surround the expertise of the experts (including me) in this field, and a nagging doubt that we have chosen the right questions to focus on (even though we did our best collectively to get those right). Perhaps this needs to be an iterative process to overcome these issues." 
Some attendees did not appear to have left the event with a clear sense of how the answers to the elicitation questions would inform the final tool that was to be created. One respondent articulated this with the comment "I don't want to criticize or pre-judge as I am not fully aware of the relationship between the questions and the final model". When asked "What barriers might prevent you adopting the resulting tools?", another respondent replied "It was unclear if the tool would be based just on the answers of the participants from the two days or if it would be also populated using facts - certain questions have factual answers such as the average failure rate of hard drives and it would be reassuring to know where available facts had been used as well as opinions. For a number of questions, the participants on the call made it clear they weren't knowledgeable about that area and so were just guessing."

There is a sense from these comments that some of those who participated in the elicitation process had reservations about the methodology and the value of questions that they were being asked. If running future events of this kind, the project team should consider what could be done to better communicate the methodology and next steps to attendees.

Quantitative data collected through the elicitation evaluation form also reflects a range of views and levels of confidence from the participants who responded (Figures 4-6).

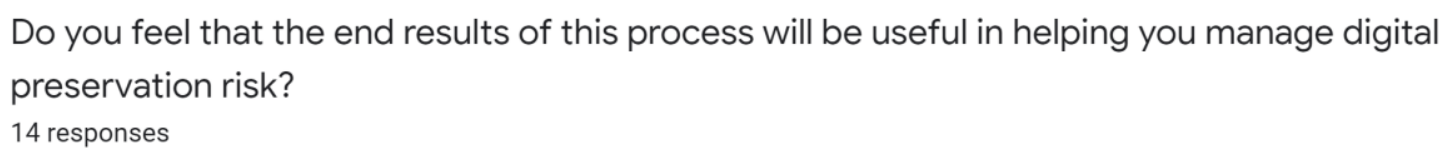

6

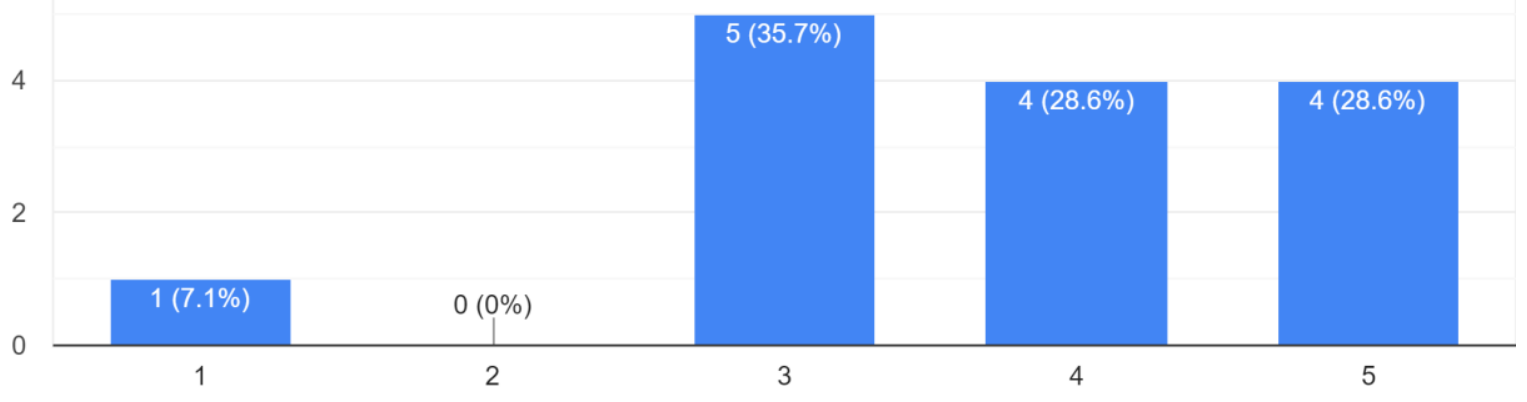

Figure 4 - Feedback from elicitation workshop evaluation form in answer to the question 'Do you feel that the end results of this process will be useful in helping you manage digital preservation risk?' (1 = Not very useful, 5 = Very useful) 
Did you feel that the experts selected to attend this workshop had the sufficient knowledge and skills to contribute to the process?

14 responses

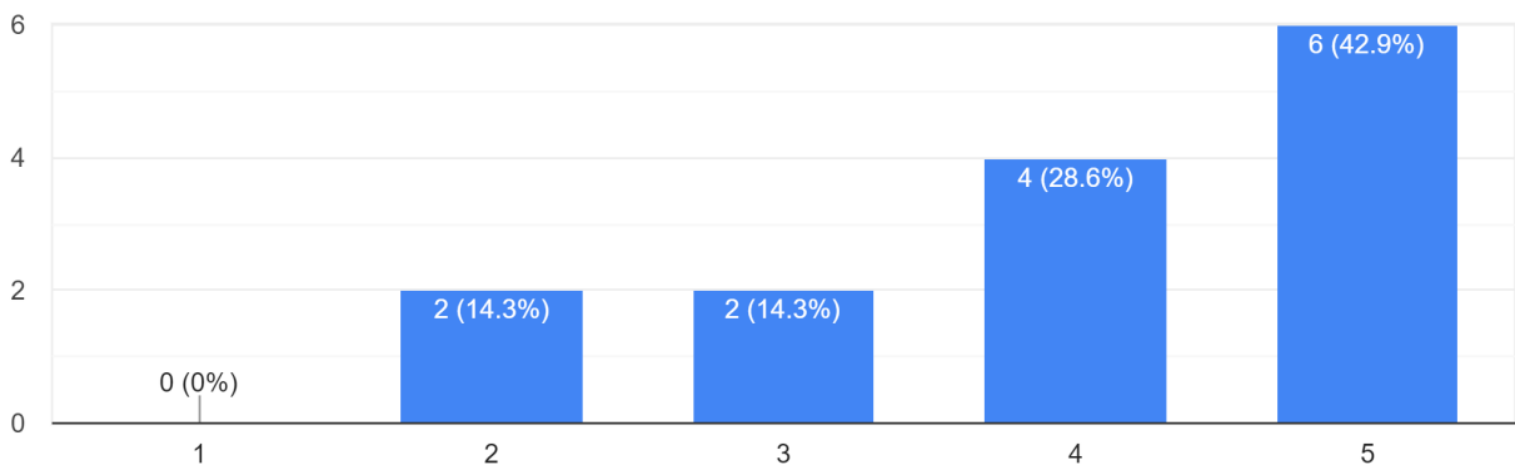

Figure 5 - Feedback from elicitation workshop evaluation form in answer to the question 'Did you feel that the experts selected to attend this workshop represented a useful cross section of the community?' (1 = Unrepresentative, $5=$ Representative)

Do you think the results are credible?

14 responses

6

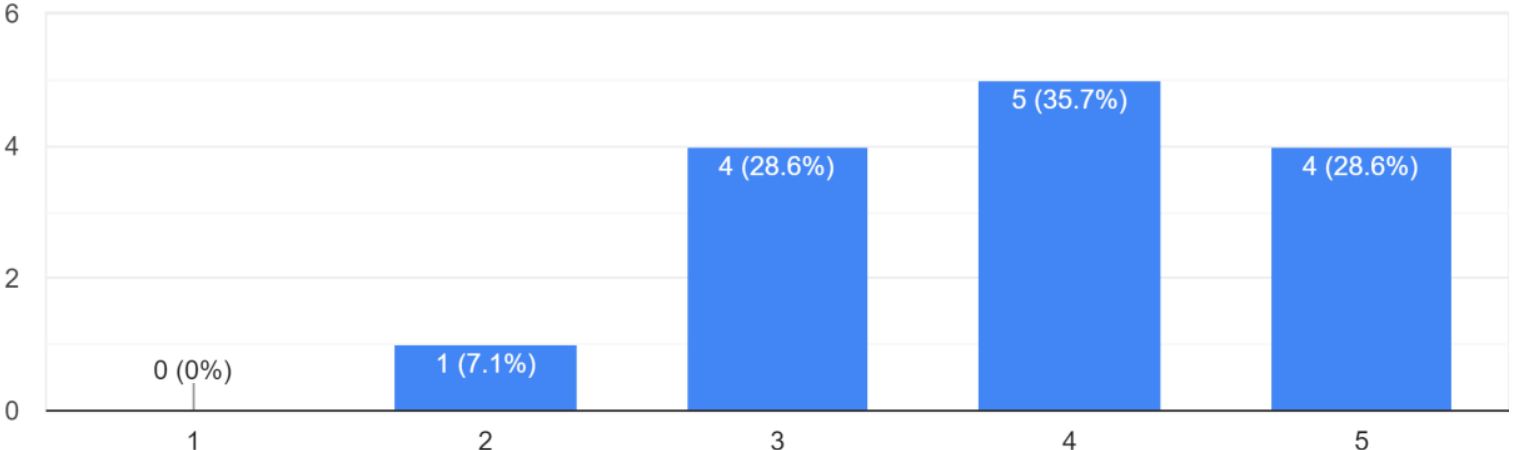

Figure 6 - Feedback from elicitation workshop evaluation form in answer to the question 'Do you think the results are credible?' (1 = Not credible, 5 = Very credible)

The end of project event held in December 2020 was attended by many of those who participated in the online elicitation process and the most recent version of the DiAGRAM tool was showcased. Though a much smaller proportion of attendees completed the event evaluation form, when similar questions were asked, the answers demonstrated an increase in confidence in the project outcomes. 
Do you think the tools and results are credible?

4 responses

3

2

1

\section{$1(25 \%)$}

$0 \frac{0(0 \%)}{0(0 \%)} \quad 0$

3

4

5

Figure 7-Feedback from end of project event evaluation form in answer to the question 'Do you think the results are credible?' ( 1 = Not credible, 5 = Very credible)

\section{Lessons learned from the project}

In interviews with the project teams at TNA and The University of Warwick a number of points were made which could usefully inform their thinking and planning if another project of this type was to be run in the future. It was universally agreed that the user interface work they were able to carry out (with money diverted from travel and face-to-face events) was incredibly valuable and they would certainly factor this in from the start next time.

Though there were some discussions around the benefits of online events and how their recent positive experience of these would lead to more online events planned by default in any subsequent project, it was recognized that the project did benefit from some face-to-face meetings in the early stages of the work and that the participants really valued the opportunity to do this before moving to a fully online mode of working. The project team reflected that attendance at lots of physical dissemination events had been planned and though online alternatives were available, they never fully replicated the experience of being able to chat informally after a presentation, making it much harder to assess audience reaction. The lack of follow up conversations in conference coffee breaks will have undoubtedly led to missed opportunities to encourage and support greater use of the tool.

The DPC noted that further downsides of offering free online events (such as the three dissemination workshops) was that the number of 'no shows' was relatively high. A fixed number of seats for these events was released and this number was capped to bring together a suitable sized audience to manage in an online workshop setting. Though these three events were very popular and sold out in record time, there were a high proportion of people who failed to attend on the day, meaning actual audience size 
was substantially reduced. This effect was unlikely to have been seen with a face-to-face workshop which typically have much higher attendance rates.

In response to this situation, the number of places made available for the third workshop was increased with an assumption that a certain percentage of those signed up would not attend. This produced a good audience size for the third workshop and some lessons have been learned for future events of this kind.

It was also noted that of those who attended the dissemination workshops, only a small proportion completed the online evaluation form. Anecdotally the DPC has noted a drop in percentage of feedback forms completed where the event and feedback form are online rather than physical, and this was certainly noted in relation to the online events associated with this project. 


\section{Conclusion and Recommendations}

\subsection{Conclusions of this evaluation}

In conclusion, the evidence gathered and reported here demonstrates that the project has met the intended outcomes and achieved what was laid out in the project bid. Indeed, it can be argued that in some areas, the project has exceeded expectations. The bid described a 'risk analysis tool and supporting statistical model' but the exact nature of the tool was not known or defined at this point. The project has produced a well thought out and professional tool that is both flexible and intuitive and this achievement should be celebrated.

This conclusion is qualified only insofar as the time scale for this evaluation is short while the time scale for culture change within the sector, and thus widespread adoption of the tool, is longer.

Some challenges were apparent in measuring the four selected outcomes in the available time frame and several assumptions had to be made to evaluate these outcomes. It is anticipated that the real impact of the project may not be felt for many years, firstly as the use of the tool gathers momentum within the archives community and secondly as the impacts of decisions made using the tool are felt.

The project has reached a wide and impressive international audience and has gained community validation in particular through its position as a finalist in the Digital Preservation Awards. Perhaps the ultimate validation for the project has been closer to home, with the use of the DiAGRAM tool internally to successfully inform and influence the recent spending review at The National Archives. For this to have happened so soon after the project work was complete is impressive and it is likely that other case studies and success stories of this nature from other institutions will emerge in time.

It is hoped that plans by the project team to further develop and support the DiAGRAM tool will continue to take shape and the tool will become widely known and used within the digital preservation community.

\subsection{Recommendations}

The evaluation therefore makes nine recommendations:

\section{Elaborate and refine the model.}

The model underlying the data is partial and could be further elaborated in breadth and depth. such as the addition of more nodes of more and increasingly granular evidence. This could be most readily achieved with participation from other national and UK archives to widen its applicability within the domain supported by NLHF.

\section{Revise and update the model with global insights.}

The evaluation has shown the value of international participation, an unanticipated benefit of the pandemic. Digital preservation is a global challenge not limited to the UK; therefore, the tool can achieve more impact abroad and become more accurate and precise if efforts are made to involve archives and sectoral partners around the world. 


\section{Maintain active communications.}

Both tool and the model are still at an early stage in terms of their deployment. For this reason, a longer-term communications strategy should be developed to support continued adoption. This should include published case studies that describe deployment in a range of different contexts and further extend familiarity with the underlying statistical method.

\section{Support users with training.}

In addition to case studies and wider communications, it is recommended that the project team investigate the provision of training materials or periodic training events that orient and support new users. This invites partnership with training providers to include the tool within relevant training materials and curricula.

\section{Design programmatic review and feedback on the model.}

The model and the data underpinning the tool fluctuate over time and therefore need periodic refreshment and updating lest they become less useful and ultimately obsolete. A programme of refreshment should be developed and include definition of roles, responsibilities and deliverables. Options to develop online methods of gathering community data and feedback should also be included in this. Such an action would further assist communication.

6. Maintain the DiAGRAM tool in line with accessibility and technical requirements. Although strictly outwith the terms of this evaluation, the DiAGRAM tool which delivers the model is also subject to obsolescence. This should be monitored with particular attention paid to accessibility. For example, the app should meet Government Digital Service (GDS) accessibility standards to be launched beyond a beta version. Moreover, it is to be anticipated that mandated requirements for accessibility and technology will continue to emerge. Efforts should therefore be made to ensure the apps ongoing compliance with these standards.

\section{Scope the opportunities for system development and integration.}

There is scope to develop the tool with more advanced functionality to encourage learning (and more nuanced scoring) as well as to allow archivists with specialist statistical skills to make more use of the tool. Integration with the broad and emergent suite preservation planning tools would also bring advantages. A research and development programme should explore these opportunities with partners.

\section{Sustain and build the community.}

The Safeguarding the Nations Digital Memory Project has worked with an important but necessarily small cross section of the archive community. Sustaining then building this group into a user community will create a virtuous circle: it will enhance the breadth of input thus improving the tool; and it will help the community to achieve its strategic goals of improved digital preservation. The DPC is a readily available catalyst for such community building.

\section{Support capability in the sector.}

It is relatively unusual for NLHF to support a project with explicit aims to support capability in the sector or to help with the development of new tools rather than the funding of new digital content. This is badly needed if the NLHF is to achieve its wider goals with respect to preserving digital content in the long term. NLHF should therefore investigate programmatic support to digital capability in the sector. 


\section{Appendices}

\subsection{Appendix 1 - List of Partners}

\begin{tabular}{|c|c|c|c|}
\hline Institution & Section & Lead Contact & Business Role \\
\hline $\begin{array}{l}\text { Digital Preservation } \\
\text { Coalition }\end{array}$ & $\begin{array}{l}\text { Standards and } \\
\text { Good Practice }\end{array}$ & Jen Mitcham & Head \\
\hline Dorset Council & $\begin{array}{l}\text { Dorset History } \\
\text { Centre }\end{array}$ & Sam Johnston & County Archivist \\
\hline Gloucestershire Council & $\begin{array}{l}\text { Gloucestershire } \\
\text { Archives }\end{array}$ & Heather Forbes & Head of the Archives Service \\
\hline The National Archives & $\begin{array}{l}\text { Digital } \\
\text { Preservation }\end{array}$ & Alex Green & Service Owner \\
\hline Transport for London & $\begin{array}{l}\text { Corporate } \\
\text { Archives }\end{array}$ & Tamara Thornhill & Manager \\
\hline University of Brighton & Design Archives & Sue Breakell & $\begin{array}{l}\text { Senior Archivist and Research } \\
\text { Fellow }\end{array}$ \\
\hline University of Leeds & $\begin{array}{l}\text { Special } \\
\text { Collections and } \\
\text { Galleries }\end{array}$ & Jodie Double & $\begin{array}{l}\text { Digital Content and Copyright } \\
\text { Manager }\end{array}$ \\
\hline Warwick University & $\begin{array}{l}\text { Applied Statistics } \\
\text { and Risk Unit }\end{array}$ & Dr Martine J. Barons & Director \\
\hline
\end{tabular}

\subsection{Appendix 2 - List of dissemination outputs}

Presentations, publications and events relating to the project are listed in the table below:

\begin{tabular}{|c|c|c|c|c|}
\hline Date & Title/Description & Type & Host & Audience \\
\hline $20 / 05 / 2020$ & $\begin{array}{l}\text { Risk Alert: Insufficient } \\
\text { Technical Metadata }^{13}\end{array}$ & Blog & DPC & Digital Preservationists \\
\hline $28 / 05 / 2020$ & Introducing DiAGRAM & Presentation & Project team & Interested TNA parties \\
\hline $16 / 06 / 2020$ & $\begin{array}{l}\text { Quantifying Digital } \\
\text { Preservation Risk (workshop 1) }\end{array}$ & Workshop & DPC & Digital Preservationists \\
\hline $22 / 06 / 2020$ & ARC Magazine article & Article & $\begin{array}{l}\text { External } \\
\text { organization }\end{array}$ & Archivists \\
\hline $30 / 06 / 2020$ & ASD presentation & Presentation & Project team & Interested TNA parties \\
\hline $03 / 07 / 2020$ & ARA journal paper & Paper & $\begin{array}{l}\text { External } \\
\text { organization }\end{array}$ & Archivists \\
\hline $17 / 07 / 2020$ & TNA blog post ${ }^{14}$ & Blog & TNA & $\begin{array}{l}\text { Archivists and their } \\
\text { public audiences }\end{array}$ \\
\hline
\end{tabular}

\footnotetext{
${ }^{13}$ https://www.dpconline.org/blog/risk-alert-insufficient-technical-metadata

${ }^{14}$ https://blog.nationalarchives.gov.uk/quantifying-digital-preservation-risks-using-statistics/
} 


\begin{tabular}{|c|c|c|c|c|}
\hline $17 / 07 / 2020$ & $\begin{array}{l}\text { Quantifying Digital } \\
\text { Preservation Risk (workshop 2) }\end{array}$ & Workshop & DPC & Digital Preservationists \\
\hline $23 / 07 / 2020$ & DiAGRAM to GFSAs & Presentation & $\begin{array}{l}\text { External } \\
\text { organization }\end{array}$ & Government Analysts \\
\hline $27 / 07 / 2020$ & $\begin{array}{l}\text { Quantifying Digital } \\
\text { Preservation Risk (workshop 3) }\end{array}$ & Workshop & DPC & Digital Preservationists \\
\hline $04 / 08 / 2020$ & SAA Research Forum & Lightning Talk & $\begin{array}{l}\text { External } \\
\text { organization }\end{array}$ & Archivists \\
\hline 06/08/2020 & DiAGRAM for DCMS analysts & Presentation & $\begin{array}{l}\text { External } \\
\text { organization }\end{array}$ & Government Analysts \\
\hline $18 / 08 / 2020$ & TNA Research Seminar & Presentation & TNA & Researchers \\
\hline $20 / 08 / 2020$ & BDAWG & Lightning Talk & $\begin{array}{l}\text { External } \\
\text { organization }\end{array}$ & Digital Archivists \\
\hline $14 / 09 / 2020$ & Trust blog for OPF ${ }^{15}$ & Blog & $\begin{array}{l}\text { External } \\
\text { organization }\end{array}$ & Digital Archivists \\
\hline $15 / 09 / 2020$ & DLM Forum webinar & Presentation & $\begin{array}{l}\text { External } \\
\text { organization }\end{array}$ & Digital Preservationists \\
\hline $16 / 09 / 2020$ & $\begin{array}{l}\text { Presentation to TNA Executive } \\
\text { Team }\end{array}$ & Presentation & TNA & Interested TNA parties \\
\hline $19 / 09 / 2020$ & IRMS Bulletin & Article & $\begin{array}{l}\text { External } \\
\text { organization }\end{array}$ & Record Managers \\
\hline $23 / 09 / 2020$ & WeMissiPress & Lightning Talk & DPC & Digital Preservationists \\
\hline $24 / 09 / 2020$ & WeMissiPress & Lightning Talk & DPC & Digital Preservationists \\
\hline $13 / 10 / 2020$ & BitCurator Users Forum & Presentation & $\begin{array}{l}\text { External } \\
\text { organization }\end{array}$ & Digital Preservationists \\
\hline $15 / 10 / 2020$ & DiAGRAM Webinar & Presentation & DPC & Digital Preservationists \\
\hline $05 / 11 / 2020$ & $\begin{array}{l}\text { TNA Annual Digital Lecture } \\
\text { poster }\end{array}$ & Poster & TNA & Researchers \\
\hline 09/11/2020 & $\begin{array}{l}\text { TNA Annual Digital Lecture } \\
\text { poster twitter chat }\end{array}$ & Poster & TNA & Researchers \\
\hline $12 / 11 / 2020$ & NDSA conference & Lightning Talk & $\begin{array}{l}\text { External } \\
\text { organization }\end{array}$ & Digital Preservationists \\
\hline $16 / 11 / 2020$ & RIMPA article & Article & $\begin{array}{l}\text { External } \\
\text { organization }\end{array}$ & Digital Preservationists \\
\hline $03 / 12 / 2020$ & TNA Audit and Risk Committee & Presentation & TNA & Interested TNA parties \\
\hline
\end{tabular}

\footnotetext{
${ }^{15}$ https://openpreservation.org/blogs/do-you-trust-our-digital-archive/
} 


\begin{tabular}{|l|l|l|l|l|}
\hline $16 / 12 / 2020$ & Warwick partnership event & Presentation & $\begin{array}{l}\text { External } \\
\text { organization }\end{array}$ & Researchers \\
\hline $18 / 01 / 2021$ & TNA Show and Tell & Presentation & Project team & Digital Directorate \\
\hline $28 / 01 / 2021$ & Bitesize & Presentation & TNA & Record Managers \\
\hline $18 / 02 / 2021$ & Blog for DCMS intranet & Blog & $\begin{array}{l}\text { External } \\
\text { organization }\end{array}$ & Government Analysts \\
\hline
\end{tabular}

\subsection{Appendix 3 - Interview questions}

Standard questions used in the interviews are listed below. Note that questions for the project team differed slightly to those used for other stakeholders.

Questions for the project team:

1. Can you cast your minds back and tell us a bit about how the project started (or how you got involved). Where did the idea come from and what was the main problem you were trying to solve?

2. What do you think worked well in this project?

3. Is there anything you felt didn't work so well?

4. Is there anything you would do differently next time? Lessons learned?

5. How do you plan to use the DiAGRAM tool in the future?

6. What plans do you have to increase engagement with this tool across the archives sector - for example, enhancing it, encouraging use, keeping underlying dataset up to date, embedding it in digipres training and workflows?

7. Are you keen to carry on with this area of research and development in the future? What are your plans?

8. How well do you think you have met the goals that you set out in the funding application?

a. Heritage will be in better condition

b. People will have developed skills

i. Have you acquired any new digital preservation (or other) knowledge or skills as a result of this project?

c. A wider range of people will be involved in heritage

d. The funded organization will be more resilient

9. Wrap up:

a. Do you have anything else you want to say that you think might be relevant to our project evaluation? Any last observations on the project and its outcomes?

\section{Questions for the wider project partners and other members of the digital preservation community:}

10. Tell us a bit about your work and how you got involved in this project or how you found out about it?

11. Have you tried using the DiAGRAM tool? When? Was it the latest version or an early prototype in the summer?

a. Did you just have a quick play with DiAGRAM or have you tried using it in earnest using accurate data from your organization or mapping out real world scenarios? 
b. Tell us how you have used the tool - what were you trying to achieve? How did it help? If the tool didn't exist, how would you have done this work in the past?

c. Did you find it easy to use?

d. Do you feel DiAGRAM could be used to help you make better decisions about how to manage the digital archives that you hold?

e. Do you have plans as to how you might use it in the future? Do you see it being used in the short, medium or long term?

12. Questions relating to the project aim that 'Heritage will be in better condition':

a. How do you think your use of the tool/your proposed use of the tool could lead to digital heritage/your digital archives being in better condition?

b. What about other's use of the tool? Do you have a sense of the wider impact beyond your own context?

13. Questions relating to the project aim that 'People will have developed skills':

a. Were you hoping/expecting to develop any particular kinds of skills by participating in the project/outputs? Which ones? Why? If yes, were these skills addressed or improved as a result?

b. Have you applied these new skills?

c. Do you think others will have developed new skills?

14. Questions relating to the project aim that 'A wider range of people will be involved in heritage':

a. Do you think your use of the tool now or in the future could lead to a wider range of people being involved in heritage? (perhaps by having better access to digital archives?)

15. Questions relating to the project aim that 'The funded organization will be more resilient':

a. Do you think the project has made your organization more resilient? If so, in what way?

16. Wrap up:

a. Do you have anything else you want to say that you think might be relevant to our project evaluation? Any last observations on the project and its outcomes?

\subsection{Appendix 4 - Web statistics}

Web access statistics were gathered for the project website and key news items or blogs relating to the project and are listed in the table below:

\begin{tabular}{|l|l|l|l|}
\hline \multicolumn{1}{|c|}{ Web page } & Description & Date & \multicolumn{1}{c|}{ Pageviews (unique) ${ }^{\mathbf{1 6}}$} \\
\hline $\begin{array}{l}\text { Safeguarding the nation's digital } \\
\text { memory }\end{array}$ & Project web page & NA & $2169(1751)$ \\
\hline $\begin{array}{l}\text { The National Archives Receives } \\
\text { National Lottery Grant for Digital } \\
\text { Project }^{18}\end{array}$ & News page & $873(666)$ \\
\hline
\end{tabular}

${ }^{16}$ As collected on $19^{\text {th }}$ January 2021

17 https://www.nationalarchives.gov.uk/information-management/manage-information/preserving-digitalrecords/research-collaboration/safeguarding-the-nations-digital-memory/

18 https://www.nationalarchives.gov.uk/about/news/the-national-archives-receives-national-lottery-grant-fordigital-project/ 


\begin{tabular}{|l|l|l|l|}
\hline $\begin{array}{l}\text { Quantifying digital preservation risks } \\
\text { using statistics }\end{array}$ & Blog post & $17^{\text {th }}$ July 2020 & $518(476)$ \\
\hline $\begin{array}{l}\text { Digital preservation project } \\
\text { shortlisted for award }\end{array}$ & News page & $\begin{array}{l}16^{\text {th }} \text { September } \\
2020\end{array}$ & $51(51)$ \\
\hline
\end{tabular}

\subsection{Appendix 5 - ResearchGate statistics}

Throughout the project, relevant resources and updates were made available to the wider community through a project page on ResearchGate. ${ }^{21}$ Statistics on reads for each item posted are available below. Note that although these figures appear not be particularly high, this is a fairly specialist research topic and 'Research Interest' as calculated by ResearchGate sits at 9.4 (higher than $29 \%$ of researchers on ResearchGate):

\begin{tabular}{|c|c|c|c|}
\hline Title & Type of content & Date & No of reads 22 \\
\hline A Bayesian model of preservation risk & Poster & July 2018 & 17 \\
\hline $\begin{array}{l}\text { Safeguarding the nation's digital memory: } \\
\text { towards a Bayesian model of digital } \\
\text { preservation risk }\end{array}$ & Conference talk & August 2019 & 596 \\
\hline Audio recording of ARA conference slides & Conference talk & August 2019 & 24 \\
\hline $\begin{array}{l}\text { A Bayesian model of Digital Preservation } \\
\text { risk for the disruptive Digital Archive }\end{array}$ & Poster & $\begin{array}{l}\text { September } \\
2019\end{array}$ & 33 \\
\hline DPRM Elicitation Workshop & Elicitation Workshop & April 2020 & 12 \\
\hline $\begin{array}{l}\text { A Collaborative Digital Preservation Risk } \\
\text { Model }\end{array}$ & Conference paper & August 2020 & 14 \\
\hline $\begin{array}{l}\text { Introduction to DiAGRAM, the Digital } \\
\text { Archiving Graphical Risk Assessment } \\
\text { Model }\end{array}$ & Conference talk & August 2020 & 2 \\
\hline $\begin{array}{l}\text { Quantifying Digital Preservation Risk: the } \\
\text { story so far (Digital Preservation Coalition } \\
\text { Webinar) }\end{array}$ & Webinar & $\begin{array}{l}\text { October } \\
2020\end{array}$ & 13 \\
\hline $\begin{array}{l}\text { [Forthcoming] Workshop: Introduction to } \\
\text { DiAGRAM [Conference postponed due to } \\
\text { COVID-19] }\end{array}$ & $\begin{array}{l}\text { Conference } \\
\text { workshop }\end{array}$ & $\begin{array}{l}\text { September } \\
2020\end{array}$ & 6 \\
\hline WeMissIPres - introducing DiAGRAM & Unconference talk & $\begin{array}{l}\text { September } \\
2020\end{array}$ & 5 \\
\hline $\begin{array}{l}\text { Digital Preservation Awards, Research } \\
\text { and Innovation, DiAGRAM }\end{array}$ & Unconference talk & $\begin{array}{l}\text { September } \\
2020\end{array}$ & 6 \\
\hline $\begin{array}{l}\text { DiAGRAM - the Digital Archiving } \\
\text { Graphical Risk Assessment Model: } \\
\text { quantifying digital preservation risks }\end{array}$ & Conference talk & $\begin{array}{l}\text { October } \\
2020\end{array}$ & 1 \\
\hline $\begin{array}{l}\text { DiAGRAM - the Digital Archiving } \\
\text { Graphical Risk Assessment Model: }\end{array}$ & Conference talk & $\begin{array}{l}\text { November } \\
2020\end{array}$ & 2 \\
\hline
\end{tabular}

\footnotetext{
${ }^{19}$ https://blog.nationalarchives.gov.uk/quantifying-digital-preservation-risks-using-statistics/

${ }^{20}$ https://www.nationalarchives.gov.uk/about/news/digital-preservation-project-shortlisted-for-award/

${ }^{21}$ https://www.researchgate.net/project/Safeguarding-the-Nations-Digital-Memory

${ }^{22}$ As collected on $19^{\text {th }}$ January 2021
} 


\begin{tabular}{|l|l|l|l|}
\hline $\begin{array}{l}\text { Rethinking practice by quantifying digital } \\
\text { preservation risks }\end{array}$ & & \\
\hline $\begin{array}{l}\text { DiAGRAM: Digital Archiving Graphical } \\
\text { Risk Assessment Model }\end{array}$ & Poster & $\begin{array}{l}\text { November } \\
2020\end{array}$ & 4 \\
\hline $\begin{array}{l}\text { DiAGRAM: Digital Archiving Graphical } \\
\text { Risk Assessment Model - A statistical } \\
\text { approach to digital archive risk } \\
\text { management and sustainability }\end{array}$ & Conference talk & January 2021 & 4 \\
\hline
\end{tabular}

\subsection{Appendix 6 - Twitter statistics}

A full list of statistics from Twitter of one of the project team's tweets using the project hashtag \#NLHF_diagram was provided for evaluation. This dataset was too large to include unedited in this report, but information about those tweets with the highest number of engagements are listed below:

\begin{tabular}{|c|c|c|}
\hline Tweet URL and description & Impressions & Engagements \\
\hline $\begin{array}{l}\text { https://twitter.com/DavidUnderdown9/status/13054933634839 } \\
\text { D7489 } \\
\text { DPC Award shortlist announcement }\end{array}$ & 3788 & 29 \\
\hline $\begin{array}{l}\text { https://twitter.com/DavidUnderdown9/status/13243997530949 } \\
\text { Announcement of final prototype }\end{array}$ & 3457 & 80 \\
\hline $\begin{array}{l}\text { https://twitter.com/DavidUnderdown9/status/13167713956706 } \\
\text { 01729 } \\
\text { First announcement of updated UI version }\end{array}$ & 3240 & 93 \\
\hline $\begin{array}{l}\text { https://twitter.com/DavidUnderdown9/status/12224544957261 } \\
\text { Starting work on the project }\end{array}$ & 2658 & 26 \\
\hline $\begin{array}{l}\text { https://twitter.com/DavidUnderdown9/status/12555270488834 } \\
49862 \\
\text { End of elicitation workshop tweet }\end{array}$ & 2485 & 119 \\
\hline $\begin{array}{l}\text { https://twitter.com/DavidUnderdown9/status/12450130572706 } \\
\text { Tal60 } \\
\text { Talk at Preservica UGM (first external talk) }\end{array}$ & 2200 & 40 \\
\hline
\end{tabular}

Further Twitter statistics were supplied for two key project tweets released from the main corporate Twitter account at TNA. Tweets sent out from this account will reach a wider audience, many of which who will not have been involved in digital heritage before. The first of these tweets in particular was considered to be a high performing tweet, with levels of engagement that were well above average. This information was collected on $20^{\text {th }}$ January 2021:

\begin{tabular}{|c|c|c|}
\hline Tweet URL and description & Impressions & Engagements \\
\hline $\begin{array}{l}\text { https://twitter.com/UkNatArchives/status/122213097297357 } \\
\text { 6192 } \\
\text { HLF funding for 'Safeguarding the Nation's Digital Memory' }\end{array}$ & 49,868 & 635 \\
\hline $\begin{array}{l}\text { https://twitter.com/UkNatArchives/status/129018818806605 } \\
\text { Model prototype released }\end{array}$ & 16,577 & 444 \\
\hline
\end{tabular}




\subsection{Appendix 7 - Digital Preservation Awards 2020 feedback}

The judging process for the Digital Preservation Awards provides an opportunity to gather feedback from the DPC Community. A complete set of feedback is listed below. These comments convey a real and significant measure of the esteem from leading practitioners from the digital preservation community around the world and were shared with the project team once the judging process was complete.

- Good discussion of previous efforts and the unique contribution this project makes, particularly in consideration of funders who need to see measurable benefits (always a concern).

- Purpose is clearly articulated.

- Looked at existing DP tools, recognized that a better tool was needed, and found it (Bayesian Networks).

- Provides a good summary of the existing DP tools and landscape, and clearly articulates the unique element this project brings (quantitative dimension to risk management).

- Outcomes are credible.

- I am looking forward to tangible implementation examples.

- Proof that digital projects are worthwhile in their own right is a benefit perhaps unique to this project.

- COVID created more opportunities to funnel project resources into development. The uniqueness in this project's funding is a stand-out positive impact for potential advocacy for the field

- Statistics presented as evidence of positive peer response are good. Tell me more! (e.g., how many participants were there?).

- Answers a pressing need with a multidisciplinary approach. Result is practical.

- Clear understanding of audience and what they need from this tool

- Clear and focused purpose

- Clear evidence for why Bayesian networks might be applied here

- The prototype shows clear innovation in the way it displays information and attempts to create quantitative comparisons

- Clear immediate benefits and the starting point for potential new ways of assessing risk

- There is a lot of potential in this project

- Good initial responses from users

- Very strong, convincing and as far as I can tell entirely new basis for executives to understand the provision of funding, policy and priority to investment in digital preservation, as well as the practical outcomes of preservation actions. This is a step change from anything that has come before.

- Once again UK TNA's thinking is a level higher than the rest of the DP community; once again their leadership means we'll all be a level up soon too.

- Love the prototype shiny app approach

- plausible requirement and broad audience

- Informing risk analysis is a difficult area.

- Useful to look outside of archival sector 
- Quantitative approach is new for DP

- Wide benefits to be realised

- Paradigm changes could be significant

- Good ROI for collaborative project

- Useful workshop feedback

- Innovative risk management tool with many implementation benefits, combining data with judgement

- The only downside I can see is that it is designed around the UK. Could (and should!) be expanded 


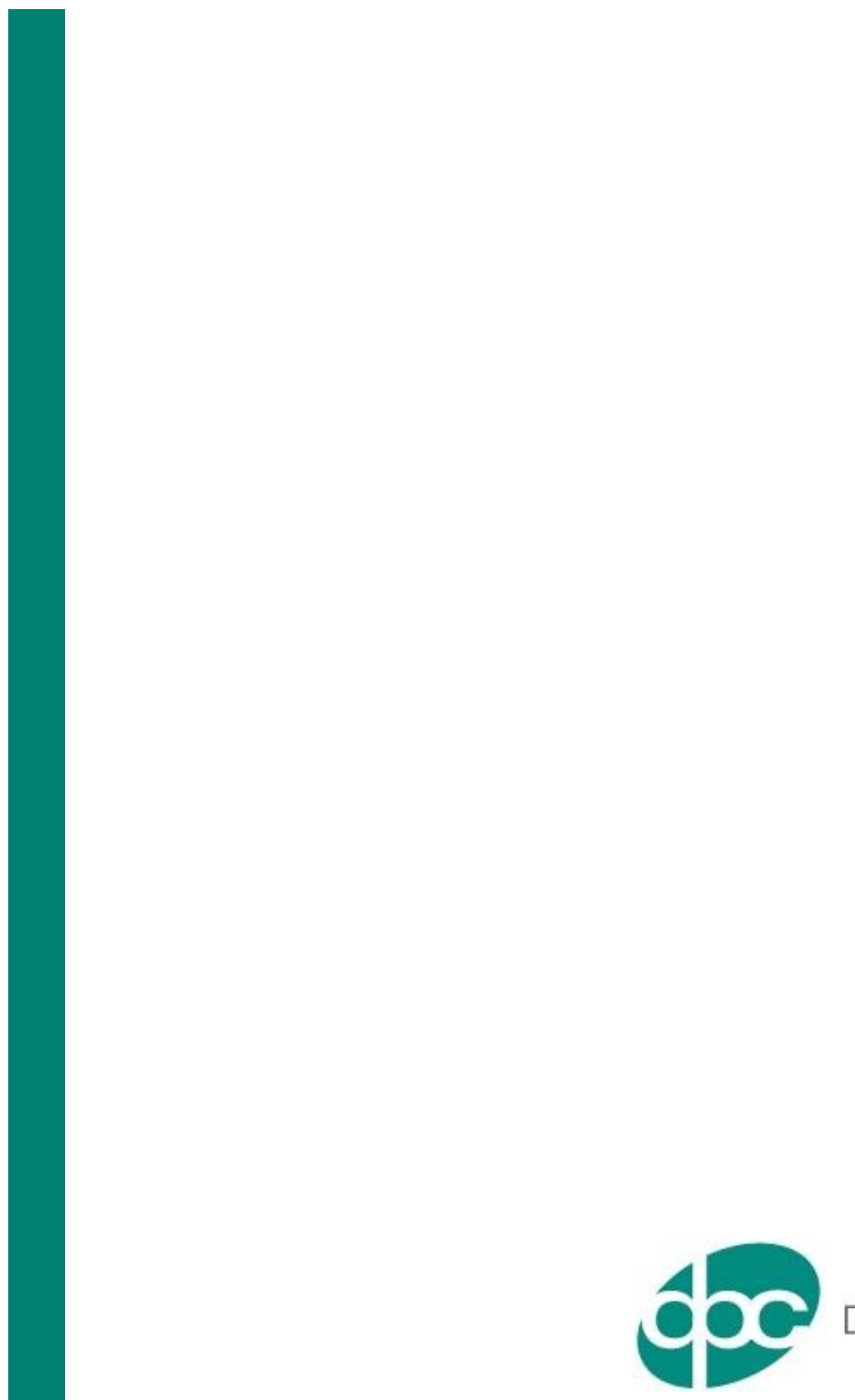

DigitalPreservationCoalition

(C) Digital Preservation Coalition 2021

Digital Preservation Coalition c/o Information Studies,

11 University Gardens, Glasgow G12 8QQ SCOTLAND

http://www.dpconline.org/ info@dpconline.org +441413302252 